\title{
Hidden Versus Revealed Attitudes: A List Experiment on Support for Minorities in Ireland
}

Frances McGinnity, Mathew Creighton and Éamonn Fahey

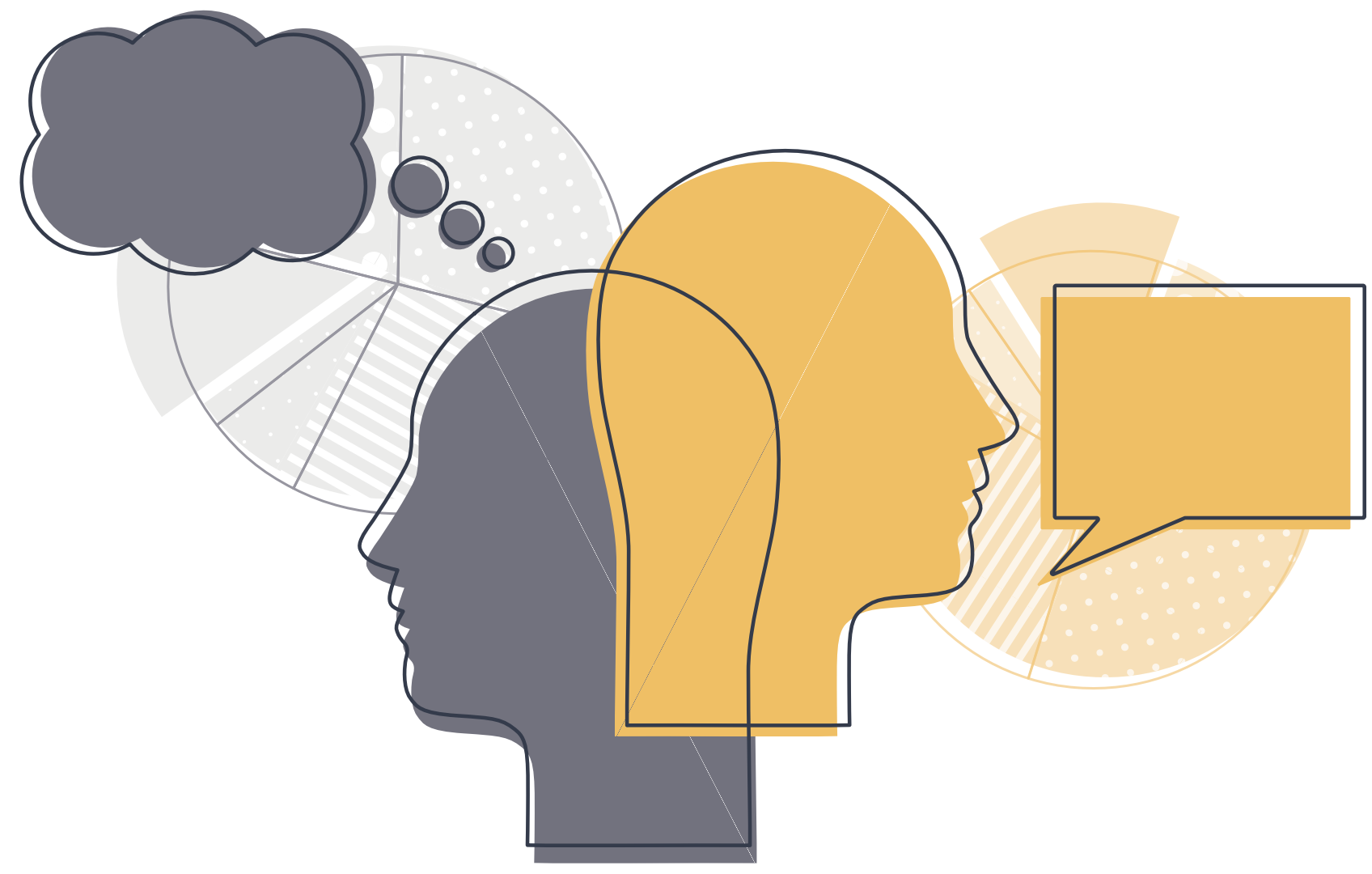




\section{Hidden Versus Revealed Attitudes: A List Experiment on Support for Minorities in Ireland}

Frances McGinnity, Mathew Creighton and Éamonn Fahey 
This report was written by Frances McGinnity, Mathew Creighton and Éamonn Fahey. It was prepared for the Irish Human Rights and Equality Commission by the Economic and Social Research Institute as part of the Research Programme on Human Rights and Equality. The report has been peer-reviewed prior to publication. The views expressed in this report are those of the authors and do not necessarily represent those of the Economic and Social Research Institute or the Irish Human Rights and Equality Commission.

The Irish Human Rights and Equality Commission was established under statute on 1 November 2014 to protect and promote human rights and equality in Ireland, to promote a culture of respect for human rights, equality and intercultural understanding, to promote understanding and awareness of the importance of human rights and equality, and to work towards the elimination of human rights abuses and discrimination.

The Economic and Social Research Institute (ESRI) is an independent research institute working towards a vision of 'Informed policy for a better Ireland'. The ESRI seeks to support sustainable economic growth and social progress in Ireland by providing a robust knowledge base capable of providing effective solutions to public policy challenges.

Available to download from www.esri.ie and www.ihrec.ie

(C) 2020. Copyright is held jointly by the Economic and Social Research Institute and the Irish Human Rights and Equality Commission.

Irish Human Rights and Equality Commission, 16-22 Green Street, Dublin 7. The Economic and Social Research Institute, Whitaker Square, Sir John Rogerson's Quay, Dublin 2

https://doi.org/10.26504/bkmnext372

ISBN: 978-0-7070-0481-5

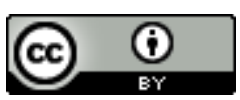

This Open Access work is licensed under a Creative Commons Attribution 4.0 International License (https://creativecommons.org/licenses/by/4.0/), which permits unrestricted use, distribution, and reproduction in any medium, provided the original work is properly credited. 


\section{FOREWORD}

I am very pleased to introduce this report Hidden versus Revealed Attitudes: A List Experiment on Support for Minorities in Ireland. The Irish Human Rights and Equality Commission is statutorily mandated to encourage good practice in intercultural relations, to promote tolerance and acceptance of diversity in the State and respect for the freedom and dignity of each person.

The publication of this report comes at a moment when the relationship between individual attitudes and systemic racism has been cast into sharp focus. One of the ways we can uncover, challenge, and change subtle, endemic racism is by being more confident that the mirror we hold up to Irish society - for example, through research which measures attitudes towards minority groups - offers a clear reflection back to us.

However measuring attitudes on sensitive topics - such as attitudes towards minority groups - can prove difficult. Social desirability bias is the theory that what people say in public is driven by social pressure to respond in a particular way, resulting in over-reporting or under-reporting particular attitudes. Accordingly, people may hide their true opinion in survey interviews.

This report presents the findings from the first list experiment conducted in Ireland. This innovative method identifies the effects of social desirability bias. This gives us a more accurate understanding of social attitudes towards different groups and how these may vary in the wider population. A better understanding of the relationship between hidden and revealed attitudes can inform the Commission's work to deliver meaningful change in public discourse, behaviours and experiences.

This is the seventh in a series of research reports prepared by the ESRI for the Irish Human Rights and Equality Commission. The aim of the IHREC-ESRI Human Rights and Equality Research Programme is to create, improve and enhance knowledge in order to provide evidence for monitoring and for the development of policy.

I would like to thank the ESRI for their continued engagement. In particular, I would like to extend my appreciation to the report's authors, Professor Frances McGinnity, Professor Mathew Creighton and Éamonn Fahey, for their work on this important subject. 


\section{THE AUTHORS}

Frances McGinnity is an Associate Research Professor at the ESRI and an Adjunct Professor of Sociology at TCD. Mathew Creighton is an Associate Professor at University College Dublin and a member of the UCD Geary Institute for Public Policy. Éamonn Fahey was a Research Assistant at the ESRI at the time of writing.

\section{ACKNOWLEDGEMENTS}

We would like to offer a special thanks to Dorothy Watson and Bernadette Ryan for their support and assistance in conducting the list experiment on which this report is based as part of the Economic Sentiment Monitor. We gratefully acknowledge the funding received from the Irish Human Rights and Equality Commission (IHREC) to support this research programme.

We would also like to thank Cliona Doherty (IHREC), Iris Elliott (IHREC), Gráinne Collins (NDA), Tania Burchardt (LSE) for their input and constructive comments as members of the research programme steering group. The report also benefited greatly from the comments of two ESRI reviewers, and an external expert reviewer, as well as Emer Smyth and Helen Russell, in their role as editors of the report. We would finally like to thank Shannen Enright, who assisted with bringing the report to publication. 



\section{TABLE OF CONTENTS}

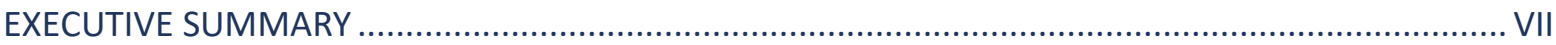

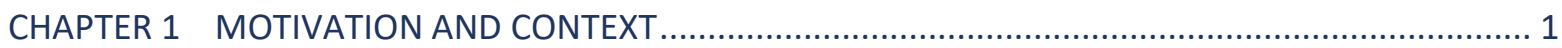

1.1 Why conduct a list experiment in Ireland?....................................... 1

1.2 Context: diversity in Ireland ............................................................. 3

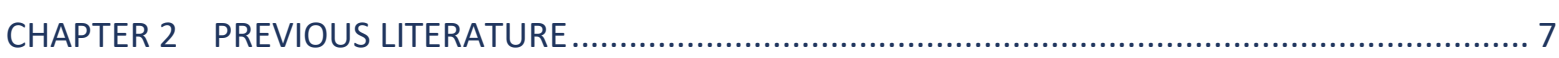

2.1 Previous findings on group differences and discrimination ......................... 7

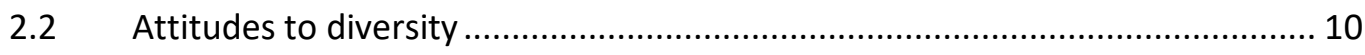

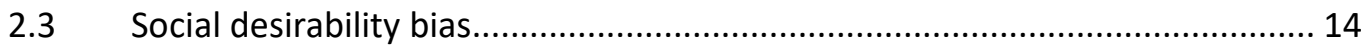

2.4 Evidence of masking from international literature ................................. 16

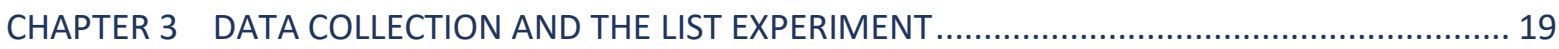

3.1 How the data were gathered ....................................................... 19

The list experiment...................................................................... 21

CHAPTER 4 ATTITUDES TO BLACK AND MUSLIM IMMIGRATION TO IRELAND: REVEALED AND

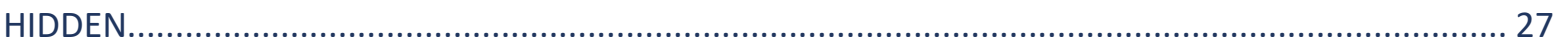

4.1 Attitudes to Black and Muslim Immigration.......................................... 29

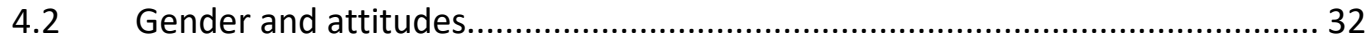

Age and attitudes ........................................................................ 34

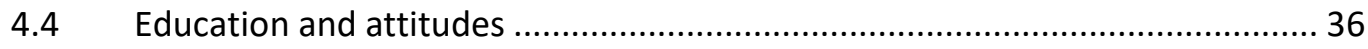

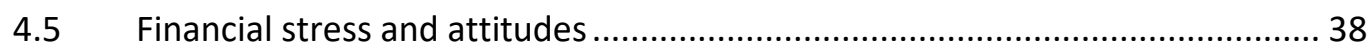

4.6 Do anonymously expressed scores differ between groups?........................ 40

Chapter summary ...................................................................... 41

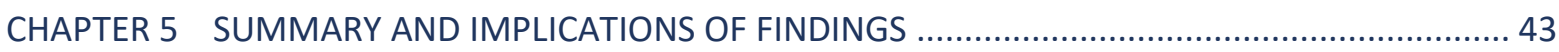

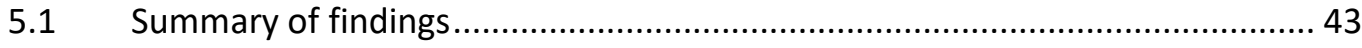

5.2 Limitations and avenues for future research ...................................... 45

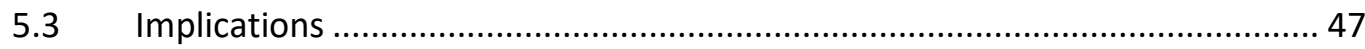

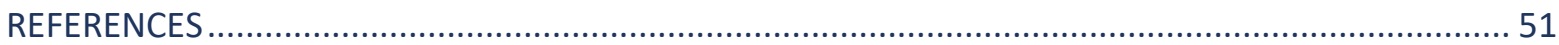

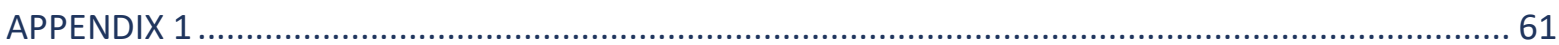

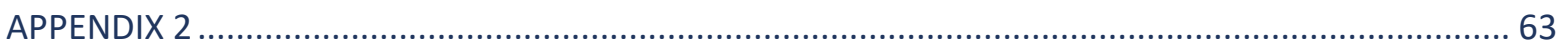




\section{LIST OF TABLES}

Table 1.1 Characteristics of Black and Muslim populations in Ireland (2016) 5

Table 4.1 Group variation in anonymously expressed support for more Black and Muslim people coming to Ireland

\section{LIST OF FIGURES}

Figure $1.1 \quad$ Number of Black and Muslim people living in Ireland .................................. 4

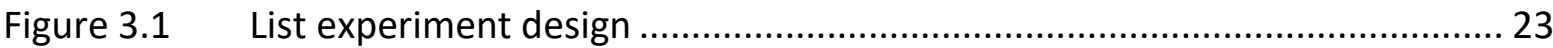

Figure 3.2 List responses: control group ............................................................... 24

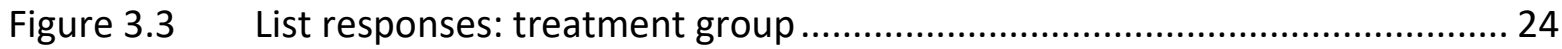

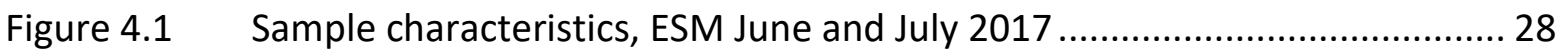

Figure 4.2 Support for Black and Muslim people coming to Ireland ............................. 30

Figure 4.3 Gender differences in support for more Black and Muslim people coming to Ireland

Figure 4.4 Age (under 50/50+) and support for more Black and Muslim people coming to Ireland 35

Figure 4.5 Educational attainment and support for more Black and Muslim people coming to Ireland

Figure 4.6 Financial stress and support for more Black and Muslim people coming to Ireland 


\section{EXECUTIVE SUMMARY}

Survey data can provide important insights on attitudes towards immigrants and ethnic and religious minorities. However, there is often a concern that people hide their negative views towards these groups in surveys and give 'socially desirable' responses. This report addresses that possible source of bias using an innovative research design called a 'list experiment', which offers respondents an anonymous way to express any negative attitudes they may have. It thus complements other research on attitudes to minorities in Ireland (McGinnity et al., 2018a), as well as more general research on equality and discrimination (McGinnity et al., 2018c). This report explores the use of a survey experiment, termed the list experiment, to identify and understand the extent to which negative attitudes towards two specific groups are concealed. The results suggest that the method could be easily extended to explore attitudes to other minority groups in contemporary Ireland.

The list experiment presents the 'treatment' group of respondents a list of items, including one sensitive item, and asks how many items they agree with. Crucially, they are not asked which of the items they agree with, just how many. A 'control' group is given the same list of items, minus the sensitive item that asks about support for the controversial topic - in this case more Muslim (or Black) people coming to Ireland. As the groups are randomly assigned and both samples are presented the same control list items, any difference between the average response to the control and treatment is due to the additional (sensitive) item. Respondents in the control group are also asked a direct question about support for more Muslim (or Black) people coming to Ireland. The difference between revealed support from the direct survey question and support from the list is interpretable as a measure of the extent to which support for immigration is over-stated or negative attitudes are hidden or 'masked'.

We use the first list experiment carried out in Ireland in two waves of the Economic Sentiment Monitor to investigate revealed and hidden attitudes to for more Black and Muslim people coming to live in Ireland. The survey captured attitudes of two nationally representative samples of adults in Ireland - approximately 1,600 individuals in total - in June and July 2017. 


\section{KEY FINDINGS}

The key finding of this report is that the masking of negative views varies by both the group in question (Black and Muslim people) and the socio-demographic characteristics of the respondent. The questions focus on immigration, that is more people from each group coming to Ireland, but we argue they are reflective of the context for these minority groups living in Ireland.

\section{Hidden and revealed attitudes to different groups}

We find that when survey respondents are asked about their views directly, they are more likely to express support for more Black people coming to Ireland than for more Muslim people. However, we also find that social pressures to exhibit tolerance are much greater when people are asked about the Black ethnic group than the Muslim group. Fifteen per cent of the sample do not support more Black people coming to Ireland but conceal this when asked directly in the survey. By contrast, we found no such masking of lack of support for the Muslim group. This is consistent with international evidence which shows that Muslims are often not subject to masking to the same extent that other groups are (Creighton and Jamal, 2015; Creighton et al., 2016; Benzeval et al., 2017). When respondents in Ireland are given anonymity in the list experiment, they are no more supportive of the Black ethnic group than the Muslim group: about half of the population support more of each minority group coming to Ireland.

At around 50 per cent, the levels of anonymously expressed support in Ireland are higher than those emerging from a similar series of experiments in the UK in 2015 and 2016. Between 30 and 36 per cent of UK respondents support Muslim immigration, and between 30 and 42 per cent anonymously express support for Black immigration in the UK, albeit that these questions are focused specifically on immigration by Black people from the Caribbean. Note also, given the design of the survey in the Irish list experiment, there is no option to express 'neutral' opinions about more Black and Muslim people coming to Ireland: there could be some people who have no opinion on the topic or 'don't mind'. Instead, the approach measures differences in the level of support expressed and masked by respondents. 


\section{Masking varies by education}

Survey data have consistently shown that people with higher educational attainment are more positive towards minorities in Ireland and elsewhere. However, this report reveals that this is largely because highly educated people tend to conceal their negative attitudes in surveys. We find that among people with third-level education, over one-quarter conceal negative attitudes to the Black ethnic group, and one-fifth mask negativity towards Muslims. By contrast, only 8.5 per cent of people whose highest educational attainment is the Leaving Certificate or less conceal lack of support for the Black ethnic group, and we find no evidence of masking among this group when they are asked about more Muslim people coming to Ireland. When we consider anonymously expressed attitudes, there is no statistically significant difference between those with higher education (third-level) and those with only Leaving Certificate qualifications (or less) in support for either the Black or Muslim groups. This is an important finding because people with decision-making power over public policy and the allocation of resources such as jobs and housing tend to have higher educational attainment.

\section{Masking varies by age}

While the effect of age on attitudes reported in previous literature is not usually as robust as that of education, we would generally expect younger people to express more positive views to minority groups than older people. Indeed, this is supported by our estimates of openly expressed support for both groups using the direct question. However, the differences between the age groups are substantially smaller when we look at anonymously expressed attitudes derived from the list. This is because masking is almost twice as prevalent among the younger group (aged 18-49) as among the older group (aged 50 or over) with respect to the question on Black immigration. However, even after this adjustment, those aged less than 50 are still much more likely to support more Black people coming to Ireland (just under 60 per cent support this) than those aged 50 or over (40 per cent support this). We find no evidence of masking among those 50 and over who are asked about the Muslim group, but over ten per cent of those under 50 mask on this item. There are no age differences in anonymously expressed support for Muslims coming to Ireland just over half of each age group support this - though note these are relatively wide age brackets. 
Masking varies by gender, but this depends on the minority group

Twenty-one per cent of men mask negative opinions towards the Black ethnic group compared to 10 per cent of women. While men seem more supportive when asked directly, the lists reveal no gender difference in anonymously expressed attitudes towards the Black ethnic group. Women, by contrast, mask negativity towards Muslims to a much greater extent. Over one-fifth of women hold but conceal lack of support for the Muslim group in the survey. While there is no difference between men and women in terms of attitudes towards Muslims when measured directly, a large and statistically significant gender difference appears on anonymously expressed scores, with women being much less in favour of more Muslims coming to Ireland (40 per cent support this) than men (67 per cent support this).

\section{IMPLICATIONS}

These findings challenge results from standard surveys. It appears that the prevalence of positive attitudes towards some minority groups may be heavily influenced by social desirability - in other words, by people hiding their true opinions in survey interviews. The extent of social desirability bias disrupts the presumption that Irish attitudes to these minorities are as positive as they seem on the face of it. While evidence of socially desirable response patterns has been documented in other countries, this is the first time this has been attempted in Ireland.

Furthermore, the results suggest that social pressure to conceal negative attitudes may affect some groups of respondents more than others. This prompts us to reassess our interpretation of how attitudes to immigration vary by age, gender and educational attainment. It also suggests that list experiments would be valuable additions to future social surveys in Ireland and elsewhere.

That is not to say that analysis of standard survey data is not valuable. Attitudes which are openly expressed in surveys still matter because they may be better predictors of certain types of behaviours and outcomes than concealed opinions. For instance, we know that negative or toxic public discourse can impact on health and well-being outcomes among minority groups. This effect can be direct, or it can occur by increasing perceptions of 
discrimination which in turn compromise mental health and well-being (Wallace et al., 2016; McGinnity and Gijsberts, 2016; Safi, 2010).

However, we argue that negative attitudes which are not expressed openly may affect decisions made regarding minority groups behind closed doors or via anonymous acts voting or recruitment being two prominent examples. While any attempt to foster interculturalism must consider directly expressed attitudes, efforts are also needed to understand and to combat more subtle, covert or coded forms of prejudice and discrimination. Accounting for the presence of social desirability bias found in this experiment can inform the development of interventions to change discriminatory attitudes using a more targeted, nuanced approach. Increasing the evidence base is the first step in that process. 



\section{CHAPTER 1}

\section{Motivation and context}

\subsection{WHY CONDUCT A LIST EXPERIMENT IN IRELAND?}

Rapid immigration during the economic boom in Ireland has meant that Ireland has become considerably more diverse in terms of ethnic and national origin in recent decades. How has the Irish population responded to this? Attitudinal data provide an important indicator of the climate towards groups like immigrants and ethnic and religious minorities. However, there is often a concern that people do not give true answers to sensitive survey questions on immigrants and ethnic and religious minorities. Instead, they may choose to conceal negative attitudes from the interviewer due to social pressures to come across as tolerant and welcoming. This phenomenon, known as 'social desirability', biases our estimates of the extent of pro- and anti-immigration sentiment, and is the subject of this analysis.

It is important to account for social desirability for a number of reasons. First, while survey data generally suggest that attitudes to immigrants and minority groups in Ireland are not particularly negative, there could be a latent anti-minority opinion that is being concealed from interviewers. None of the large data gathering programmes on attitudes such as the European Social Survey, the European Values Study, or the Eurobarometer include a mechanism to account for social desirability bias. Second, previous research has found a large difference in attitudes to immigrants in Ireland between certain groups in the population, such as people with high and low educational attainment (McGinnity et al., 2018a). If social desirability bias is higher among the highly educated, we might be overestimating the difference in attitudes between those with higher and lower education. It may be that the highly educated are not more tolerant but are just more likely to conceal their negative attitudes. If this is the case, education per se may not lead to more tolerance of diversity. Finally, we know very little from survey data about attitudes to the Black ethnic group in Ireland, except they are much more likely to experience discrimination (McGinnity et al., 2017). Fahey et al. (2019) found less directly expressed support for Muslim immigration than for White immigration in Ireland in 2014. Uncovering both revealed and hidden attitudes to both the Black and Muslim groups might be instructive in understanding 
discrimination towards ethnic and religious minorities in Ireland and the groups' experiences here.

List experiments have been used internationally to measure directly and anonymously expressed attitudes to sensitive topics such as immigration policy preferences (Janus, 2010); attitudes towards certain immigrant groups like Muslims (Creighton and Jamal, 2015; Creighton and Strabac, forthcoming) and attitudes to gay marriage (Glynn, 2013). ${ }^{1}$ List experiments have also been used to investigate socially undesirable behaviour, such as shoplifting, drink driving, illicit drug use, marital infidelity and tax fraud (Krumpal, 2013).

Moreover, work that has considered attitudes toward immigrant groups by race or religion has revealed significant reluctance to reveal intolerance. In work in the US on extending citizenship to legal Muslim and Christian immigrants, support for both immigrant groups was similar but deviated significantly when anonymity was provided (Creighton and Jamal, 2015). In the Netherlands, support for Muslim immigrants is significantly lower when expressed via a list experiment (Creighton, forthcoming). Similarly, when considering race, work in the US (Bazo-Veinrich and Creighton, 2018) suggests that opposition to immigration and whether it is concealed varies by the ethnicity of the respondent, with Black and White respondents much more likely to mask opposition than Hispanic respondents. In the Netherlands (Creighton et. al., 2019a; 2019b), list experiments revealed that respondents reported significantly less support for immigrants defined as the same race as the respondent when measured via a list experiment. Similarly, in Norway, attitudes toward Muslim newcomers are often masked (Creighton and Strabac, forthcoming).

This project uses the first list experiment conducted in Ireland. It was conducted in the summer of 2017, and probed respondents about their views on the Black ethnic group and the Muslim group. These are particularly salient minority groups. Black people report high levels of discrimination in both the labour market and access to services in Ireland

Directly expressed attitudes refer to opinions that are openly revealed to interviewers in survey settings. Anonymously expressed attitudes are group-level opinions that are measured by a list experiment under conditions of permanent guaranteed anonymity. 
(McGinnity et al., 2017); while debates on Muslim immigration have become very prominent in many European countries in recent years (Helbling, 2012).

\subsection{CONTEXT: DIVERSITY IN IRELAND}

This experiment analyses responses to questions about more Black and Muslim people coming to Ireland as a way of capturing attitudes to the groups more generally. Here we provide a description of the resident Black and Muslim populations using census data.

Although a large proportion of recent immigration has been from other European countries, and most immigrants have been White, Ireland has seen increased religious and ethnic diversity in the past 25 years. While the CSO publishes census data on religion dating back to 1891, Muslims were enumerated separately from the 'other' religion category for the first time in 1991, when they numbered 3,875. Figure 1.1 shows that over the period 1991-2016, the number of Muslim people in Ireland has increased steadily to 62,000 in 2016. Data on ethnic and cultural background were first collected in 2006. In this year, the census revealed that there were 44,318 Black people living in Ireland. The Black population also grew, but this increase was concentrated in the 2006-2011 intercensal period. By 2011 just over 65,000 respondents defined their ethnicity as Black on the Census, and this number was similar in $2016 .^{2}$ 


\section{FIGURE 1.1 NUMBER OF BLACK AND MUSLIM PEOPLE LIVING IN IRELAND}

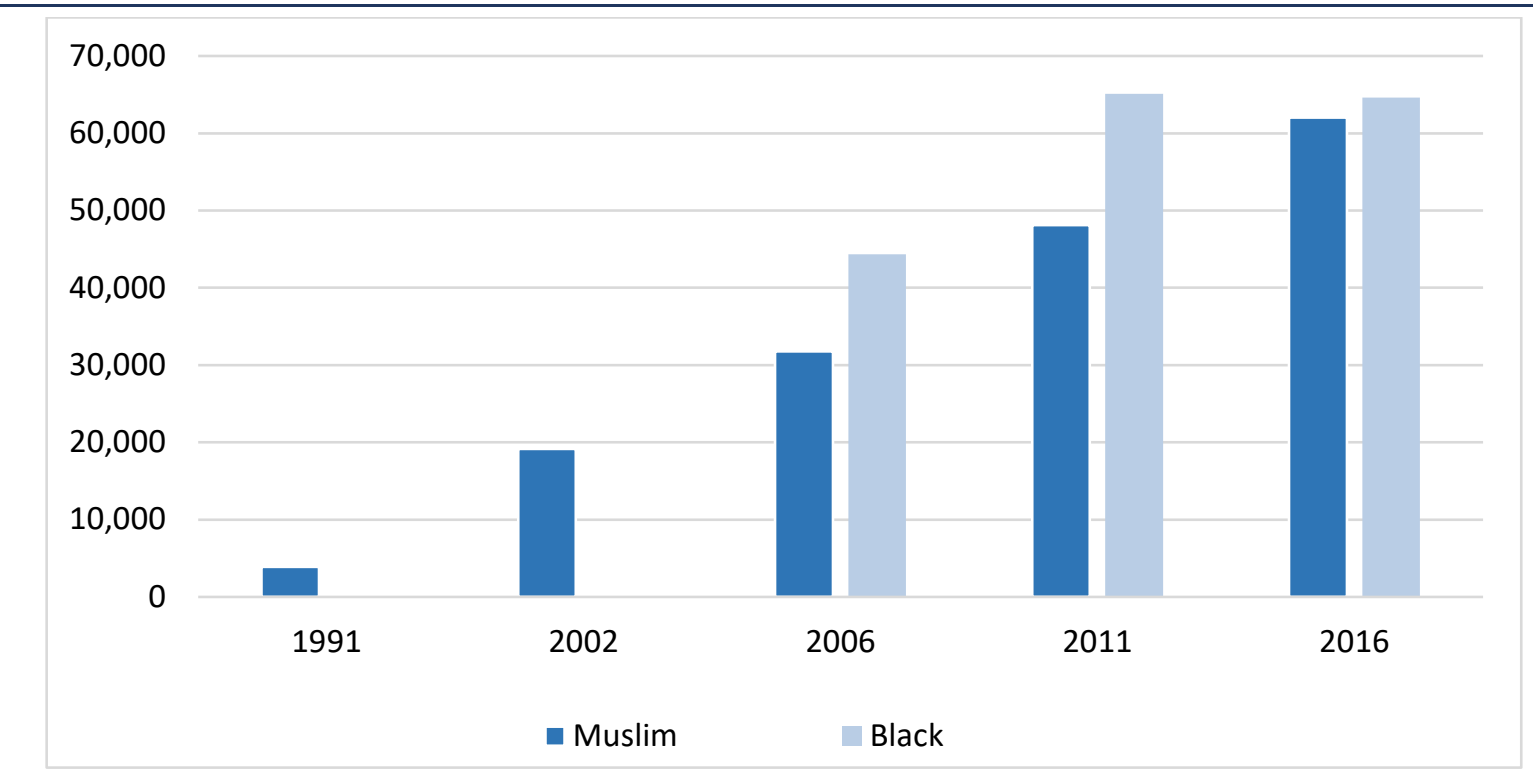

Source: $\quad$ CSO Statbank Tables E7016, E7057, C0507, C0501 and B1201.

Just under 30 per cent of Muslims and 38 per cent of Black people were born in Ireland.

A further 12,442 Muslims were born in Pakistan, accounting for just over 20 per cent of the total. Over half (53 per cent) of Black people were born in African countries and over one-quarter have Nigerian origins. Approximately half of each group report Irish nationality in the census, but both groups are very diverse in terms of country of origin (McGinnity et al., 2018b).

These minority groups perform well on some indicators of integration and social inclusion, but poorly on others. Both groups, but in particular Black people, are highly educated. The 2016 Census shows that 63 per cent of Black people and 57 per cent of Muslims have tertiary education, compared to 48 per cent of the total population. However, this educational advantage does not translate to the labour market. Unemployment is more than twice as prevalent among both the Black and Muslim communities as in the entire population; and Black people are considerably under-represented among managers or professionals. In addition to having higher unemployment rates, both groups have considerably lower employment rates than the total adult population, partly because they are more likely to be students. These patterns can in part be explained by the age profile of the groups, which are a good deal younger on average than the rest of the population. 
TABLE 1.1 CHARACTERISTICS OF BLACK AND MUSLIM POPULATIONS IN IRELAND (2016)

\begin{tabular}{l|c|c|c}
\hline & Black \% & Muslim \% & Total Population \% \\
\hline Third-level Education & 63 & 57 & 48 \\
\hline $\begin{array}{l}\text { Unemployed } \\
\text { Managers/Professionals }\end{array}$ & 20 & 18 & 8 \\
\hline $\begin{array}{l}\text { Students } \\
\text { Aged under } 35\end{array}$ & 24 & 22 & 11 \\
\hline $\begin{array}{l}\text { Source: } \\
\text { Note: }\end{array}$ & 57 & 68 & 47 \\
\hline & $\begin{array}{l}\text { Own calculations from Statbank tables E8001, E8008, E8010, E8011, EB009, E8065, E8063, E8055. } \\
\text { uses the entire population enumerated on Census night as its base, but its breakdown by ethnicity is based on the 'usually } \\
\text { resident population'. This means that the figures would not be comparable. }\end{array}$
\end{tabular}

It is striking how closely the profiles of Black and Muslim people resemble one another. Part of the reason for this may be that a considerable number of people fall into both categories. According to the 2016 Census, approximately 18.5 per cent of Muslims are Black $(11,500$ individuals), and a similar proportion of Black people are Muslims. Recent Irish research has also found these groups to be disadvantaged in ways that are not picked up by the headline education and primary economic status indicators. This is discussed in Chapter 2. 



\section{CHAPTER 2}

\section{Previous literature}

This report seeks to contribute to a growing literature on immigration and ethnic and religious diversity in Ireland. Broadly speaking, there are three strands of research on this topic. First, socio-economic differences between these minority groups and the majority can be identified and studied with a view to understanding their causes, one of which may be discrimination. These differences typically cover the areas of employment, income, housing, health and education (e.g. McGinnity et al., 2018b; 2018c). Second, discrimination against these minority groups can be studied directly using a range of methods. These include field experiments, analysis of legal records/complaints, analysis of self-reports of discrimination (McGinnity et al., 2017; 2018c) or qualitative methods (Michael, 2016; Carr, 2016). Finally, researchers can frame the issue of minority integration as an issue for the majority population, by examining their attitudes to immigration and diversity (McGinnity et al., 2018a).

\subsection{PREVIOUS FINDINGS ON GROUP DIFFERENCES AND DISCRIMINATION}

Recent work illustrates that there is considerable variation in socio-economic outcomes between ethnic and religious groups in Ireland. McGinnity et al. (2018c) use data from the QNHS Equality Modules to investigate labour market outcomes among Black survey respondents and compare these outcomes between Irish and non-Irish citizens. Both low employment rates and poor representation in highly paid jobs are found among Black nonIrish citizens, and these relationships persist even when other socio-demographic factors such as age, education and duration in Ireland are controlled for (McGinnity et al., 2018c). Among Black Irish citizens there is no difference in overall employment rates after controlling for socio-demographic factors, but members of this group are much less likely to hold managerial/professional positions. Overall, the study concludes that ethnicity is influencing labour market outcomes, and that the Black group are disadvantaged relative to White Irish respondents.

Research based on other data shows that African nationals, over two-thirds of whom are Black, are disproportionately at risk of poverty, unemployment, and exclusion from the 
labour market (O'Connell, 2019). Less quantitative research has been carried out on outcomes among Muslims in Ireland. Grotti et al. (2018) found Muslims to be at much higher risks of homelessness than the rest of the population. This study also found high rates of homelessness among Black people. As shown in Chapter 1, Muslims in Ireland are more likely to be unemployed than the rest of the population, despite being more likely to have a third-level qualification (McGinnity et al., 2018b).

One approach to understanding how inequities in outcomes emerge for ethnic minorities is to use surveys to ask respondents directly about their experience of discrimination. While reports may vary depending on the perspective of the respondent, the strength of this method lies in the ability to draw on large and representative samples and to cover a wide range of situations - e.g. the labour market, housing market, or interaction with government or private businesses (Pager and Shepherd, 2008). ${ }^{3}$ In Ireland, Black people are also among the most at-risk groups in terms of the experience of discrimination across a range of settings. Controlling for a number of other factors, Black people were found to be three times more likely than the White Irish group to report experiencing discrimination in the workplace (McGinnity et al., 2017). This is true regardless of whether they are Irish citizens or not (McGinnity et al., 2018).

These findings are supported by recent research by the European Fundamental Rights Agency on the experience of discrimination among Black people in Europe. They find that 32 per cent of Black people from sub-Saharan Africa living in Ireland report having experienced discrimination in the labour market, in education (as parents/guardians) or in housing on the basis of the colour of their skin. A further 28 per cent report experiencing this kind of discrimination on the basis of their ethnic origin. These figures are above the average of 12 European countries included in the study, though the samples do differ somewhat depending on the country (FRA, 2018). ${ }^{4}$

Qualitative research has also documented instances of racism against certain minority groups in recent years. Michael (2016) draws on information from iReport, an online

3 This method can also be combined with others - such as an analysis of outcomes - to give a more comprehensive account of the situation of minority groups (Silberman et al., 2007).

$4 \quad$ Given the challenges of surveying the minority groups studied, sampling strategies varied somewhat across the countries in the study (see FRA, 2017, for more details). 
reporting tool for discrimination and racist incidents, to document the nature of Afrophobia in Ireland. The report shows that people of African descent or origin experience Afrophobia in diverse ways, with experiences ranging from workplace discrimination to violent assault. Similarly, Carr (2016) provides a detailed account of the experience of Islamophobia in Dublin. This study employed a careful qualitative design, with nearly 70 individuals from diverse ethnic and national backgrounds interviewed. Like with Afrophobia, racism and discrimination against Muslims occurs in several arenas of public life, including on public transport, in education and in employment.

To get a more complete picture of the experience of immigrants and ethnic minorities in Ireland, it is crucial to consider the extent to which the majority population fosters an inclusive environment. Understanding this can yield insights into the emergence of discrimination and broader public perceptions of immigrants and ethnic minorities. Field experiments, sometimes referred to as audit studies, provide compelling evidence in the areas of employment and housing (Neumark, 2018). Typically, in a field experiment, two matched fictitious candidates (one from a majority group, one from a minority group) apply for the same job or accommodation and responses are recorded, allowing researchers to measure the extent of discrimination (McGinnity and Lunn, 2011; Zshcirnt and Rudin, 2016). McGinnity et al. (2009) in their field experiment in Ireland in 2008 found that candidates with Irish names were twice as likely to get called for interview as candidates with African, Asian and German names. ${ }^{5}$ In a recent study of discrimination in the housing market in Ireland, Gusciute (2019) found that Polish applicants were less likely to be invited to view a rental property than Irish applicants, and Nigerian applicants were least likely to be invited to view a property. For all three groups, men were disadvantaged relative to women.

Laboratory experiments have been used to test for discriminatory decision-making and to try to understand the nature of discrimination. Vignette studies simulate personnel decisions made by employers or managers by presenting participants with hypothetical scenarios regarding selection of job candidates for hiring, or of employees for training or promotion: these studies often subsequently elicit attitudes towards the groups to which

5 Results suggested somewhat higher discrimination against African candidates than the other two minorities, but this was not statistically significant, perhaps due to there being a relatively small sample size. 
these workers belong (Neumark, 2018). Another method of assessing discrimination is to measure trends in successful legal or tribunal cases in a country over time. This has the advantage of independent adjudication of whether discrimination took place but does not give an accurate measure of incidence or prevalence of discrimination in society more broadly. ${ }^{6}$

\subsection{ATTITUDES TO DIVERSITY}

The experience of immigrants and ethnic and religious minorities is heavily influenced by the way in which they are perceived by the majority or host population. Most studies capture this dimension by analysing data garnered from representative surveys. This approach seeks to provide a balanced view of the general population. In addition, using surveys fielded in multiple countries (such as the European Social Survey or the Eurobarometer) allows for cross-national comparison. Here we discuss the theory, findings and measurement challenges associated with this literature.

\section{Theory}

Various explanations have been put forward in the literature to explain negative attitudes. Perhaps the most commonly invoked explanation is social identity theory, which states that people construct in-groups and out-groups, and exaggerate the positive qualities of the former over the latter. Branching from this general theoretical trunk, mid-range theories have emerged to understand the proximate mechanism by which negative views of outgroups (e.g. immigrants or ethnic minorities) emerge. A core explanation put forward is the notion of threat, which captures the perception that minority groups, and in particular immigrants, compete to define the economic, cultural and social landscape of a given society. This perceived threat can be real - relating to jobs, housing, or security - or symbolic - concerning threats to the majority culture or values.

Although feelings of threat are associated with negative views of minority groups and immigration, evidence suggests that social interaction can moderate the effect. Contact between individuals from different groups may reduce prejudice and modify stereotypes,

$6 \quad$ Evidence from Ireland suggests only 10 per cent of those affected by discrimination took official or legal action (McGinnity et al., 2012). 
depending on whether the contact is experienced as positive or negative (Pettigrew and Tropp, 2011). McGinnity et al. (2018a) find that in Ireland, positive social contact with those of a different race/ethnic group is associated with more favourable attitudes to the impact of immigration regardless of the frequency of contact. ${ }^{7}$

The concept of ethnic hierarchies is an implicit ranking of ethnic groups (Hagendoorn, 2016). To some extent, ethnic hierarchies draw on cultural distance, where groups perceived as 'more different' tend to have less status and thus rank lower in the hierarchy. Cultural distance often reflects visible markers such as skin colour and dress. There is evidence that Muslims are often situated near the bottom of the ethnic hierarchy both in Ireland (Mac Gréil, 2011) and elsewhere (Creighton and Jamal, 2015; Snellman and Ekehammar, 2005; Verkuyten and Kinket, 2000).

\section{Empirical findings}

McGinnity et al.'s (2018a) analysis of the European Social Survey is the most recent empirical evaluation of attitudes in Ireland. They find that people's appraisals of the value of immigrants to the country's economy, society and cultural life are broadly in line with other countries of Western Europe. ${ }^{8}$ On a scale of zero to ten, average Irish scores on these issues range from five to six. There is some evidence that these attitudes track the performance of the Irish economy over time.

McGinnity et al. (2018a) also found that some individual characteristics of the respondents are strong predictors of these attitudes. Highly educated respondents are much more positive about immigration than those with lower educational qualifications, and respondent financial stress is associated with more negative attitudes. Contrary to much

7 The authors note that as both indicators (social contact and attitudes to immigration) were measured at the same point in time, they could not establish definitively whether contact influences attitudes or attitudes influence contact.

8 The European Social Survey asks people the following three questions: 'Would you say it is generally bad or good for Ireland's economy that people come to live here from other countries?'; 'And, using this card, would you say that Ireland's cultural life is generally undermined or enriched by people coming to live here from other countries?'; 'Is Ireland made a worse or a better place to live by people coming to live here from other countries?'. Responses are provided on an eleven-point scale ranging from 0 to 10. 
of the international research, attitudes to immigration did not vary significantly according to age.

McGinnity et al. (2018a) also present results from an analysis of attitudes towards Muslim immigrants. Irish-born European Social Survey respondents were asked to what extent Muslims from other countries should be allowed to come and live in Ireland. Among the 11 West-European nations considered for comparison in the analysis, Ireland is ranked second lowest, with only 40 per cent saying that Ireland should allow 'many' or 'some' Muslims to come. Excluding the current report, there are no recent data on attitudes towards Black people in Ireland.

A more positive picture of Irish attitudes towards immigrants emerges from an alternative measure developed by Gallup known as the 'Migrant Acceptance Index'. This composite measure is comprised of scores relating to a direct question on immigrants living in the respondent's country and two questions on 'social distance'. In this case, the social distance questions pertain to having an immigrant as a neighbour and an immigrant marrying a close relative. Ireland scores 7.74 out of a maximum of nine, ranking it second in the European Union and tenth in the world. A similar picture emerges from Eurobarometer measures of social distance, where Ireland ranks third, behind Sweden and Spain, on levels of comfort with having an immigrant as a friend, colleague, neighbour, doctor, family member or manager (TNS, 2018).

\section{Measurement challenges}

One challenge in interpreting the findings of surveys of attitudes of the majority population is variation in question wording. Scholarship in this area has covered a wide array of topics including immigrants, religious groups (such as Muslims), ethnic groups (such as Black people) and political/legal groups (such as refugees). Some questions ask about immigrants or racial groups living in the host country, while others ask about attitudes towards the process of immigration. A common set of questions considers social distance, i.e. the respondent's feelings about having a minority group member as a boss or having one marry into the family. Another approach is to ask about respondent's general feelings/warmth towards a group through a 'feelings thermometer'. Response categories also vary between studies. Some offer binary yes/no responses, but in other surveys responses are ordinal 
(e.g. strongly agree, agree, etc). Feeling thermometers typically produce distributions that range from zero to 100 .

That said, it is important to note that despite the diversity of questions and response options used in the field, the responses will typically correlate with one another. For instance, many of the most influential texts in this area use the terms 'immigration' and 'immigrants' interchangeably (Mayda, 2006; Hainmueller and Hiscox, 2010). Furthermore, immigration tends to overlap with broader concepts of ethnic and religious diversity. Both Irish and international research has found a strong link between attitudes towards the process of immigration and policies which allow for it on one hand, and attitudes towards race and immigrants on the other (McGinnity et al., 2018; Ward and Masgoret, 2008). We therefore argue that attitudes to Black and Muslim rights holders in Ireland will be very closely linked to attitudes towards the process of more Black and more Muslim people coming to Ireland.

More serious concerns regarding the validity of traditional measures of attitudes have emerged from the field of social psychology. One problem is that people often hold unconscious biases which are not revealed in surveys. Another concern is that attitudes to diversity may be influenced by the settings in which they are expressed. This means that attitudes articulated in a survey may not translate to other settings, such as hiring, voting and daily interaction with minorities. In particular, research has shown that survey respondents tend to conceal negative or 'socially undesirable' opinions from survey interviewers, for fear of appearing prejudiced.

These concerns regarding the measurement of attitudes and the bias introduced by reporting socially desirable responses have inspired the development of several innovative solutions. A lab-based approach is the Implicit Association Test (IAT), which addresses respondents' unconscious biases. Participants are prompted to match minority names or faces to positive and negative words or concepts as quickly as possible. Participants who are relatively slower (faster) in matching minorities to positive (negative) words/concepts are deemed to hold a bias against the minority group (see below for more detail).

Several approaches have also been proposed to resolve the issue of social desirability bias. One option is to investigate the effects of negative attitudes, such as online hate speech, 
directly. A particularly innovative recent study in Ireland by Siapera et al. (2018) used data scraped from Twitter and Facebook to analyse patterns of 'racially-loaded toxic' online speech. They analysed the content of around 6,000 entries, focusing on a variety of groups, including immigrants, Black people and Muslims. Anti-immigrant discourse was found to be focused on the financial/fiscal burden of immigration (welfare and housing) and how morally deserving or otherwise immigrants are. Islamophobic discourse focused on the topics of misogyny/sexual deviance, terrorism and the clash of civilisations. Racist speech against Black people incorporated anti-immigrant and Islamophobic tropes, but also centred on reinforcing stereotypes such as laziness and criminality (Siapera et al., 2018). The authors point out that online racist speech can be thought of as a continuum, with extreme, overt racist speech at one end, and more subtle, coded racist speech at the other end. The latter is less clear and more difficult to decode but is also problematic as it seeks to 'racialise' and demean the target group.

An alternative but less commonly used approach to circumvent social desirability bias is to employ qualitative research. This is the method used by Byrne (2014) in a study of attitudes to immigrants and immigration among Irish professionals. Consistent with the survey literature's concerns about socially desirable responding, the study found that participants tailored the expression of their attitudes depending on the social group they were interacting with, suggesting that qualitative and quantitative approaches need to be cognisant of the risk of bias in reporting of intolerance.

In an effort to both address the problem of social desirability bias and provide generalisable and representative results, an increasingly common technique is the list experiment. This approach, described in greater detail below, offers respondents absolute and permanent anonymity when expressing their views about controversial or sensitive topics, and is the method used in this report. In addition, it provides estimates that are comparable to standard direct questions in surveys, which offers a degree of comparability that qualitative, lab-based and social media evidence cannot.

\subsection{SOCIAL DESIRABILITY BIAS}

Evidence is mounting that surveys struggle to capture attitudinal data for controversial topics. Research has found that controversial opinions change depending on the extent to 
which anonymity is guaranteed (Phillips and Clancy 1972; Presser and Stinson 1998; Arnold and Feldman 1981; Kuklinski et al., 1997a; 1997b; Davis and Silver, 2003; Kuran and McCaffery, 2008; Heerwegh, 2009). For topics as distinct as plagiarism for undergraduate students (Coutts et al., 2011) to vote-buying (Kiewiet de Jonge and Nickerson, 2015) to attitudes to gay marriage (Glynn, 2013), direct questions have consistently failed to match objective evidence from settings in which subjects are given the opportunity to reveal their preferences anonymously.

Theoretically, masking attitudes that are interpretable as controversial (e.g. racist, homophobic, Islamophobic) is part of a general strategy employed by individuals to manage how they are seen by others. This presentation of self reflects front-stage, (distinct from back-stage) aspects of ourselves that can be strategically limited in their open expression (Blumer, 1969; Goffman, 1959; Kuhn, 1964; Stryker, 1980). Individuals anticipate how a given opinion will be interpreted and, depending on whether it could be stigmatised, this opinion could be deemed socially undesirable and left unexpressed as part of a strategic presentation of self (Goffman, 1963; Stryker, 1980).

The key finding of empirical work in this area is that respondents adapt their answers to the perceived expectations of survey interviewers, which, depending on the question, leads to an over- or under-reporting of a given controversial attitude. Of note, the intentional masking of attitudes is distinct from intolerance that persists at an unconscious level. In other words, masked sentiment reflects a degree of intentionality that unconscious and implicit prejudices do not. The difference between what people say upon being asked directly and what they might express privately is driven, in theory, by social pressure to offer a response perceived to be socially desirable and/or acceptable. This pressure and the resultant upward or downward bias in the survey responses, termed 'social desirability bias', has informed a large body of evidence in recent decades suggesting that mis-reporting of certain attitudes can lead to systematic errors when calculating the prevalence of a given belief (for a recent review see Krumpal, 2013). It has therefore become increasingly recognised that social desirability bias should be accounted for in measuring attitudes and in investigating the causes of negativity towards certain groups. 
That said, it is also important to monitor the prevalence of overt expressions of opposition or support for minority groups. Openly expressed negativity towards a certain group has tangible impacts on the members of that group. Research has shown that overt hostility, harassment and negative media coverage can increase perceptions of discrimination and deteriorate health, well-being and performance outcomes (McGinnity and Gijsberts, 2016; Williams and Medlock, 2017; Paradies, 2006; Safi, 2010, Wallace et al., 2016).

\subsection{EVIDENCE OF MASKING FROM INTERNATIONAL LITERATURE}

There is evidence that anti-immigrant sentiment is under-reported in surveys. In the United States, Janus (2010) found it was significantly more prevalent in the population when measured under conditions of absolute and permanent anonymity than when it was asked directly on a survey. Creighton et al. (2015) extended this work and found that openly expressed anti-immigrant sentiment hardened in the United States after the Great Recession, but that no such increase in intolerance was recorded once respondents were allowed to express themselves anonymously. In other words, underlying sentiment changed little during this period, indicating that economic shocks affect social desirability bias more than underlying attitudes. Similarly, measures of immigrant policy preference (Knoll, 2013a) and nativism (Knoll, 2013b) are linked to social desirability bias and the misreporting of attitudes toward immigrants.

The extent to which survey respondents conceal negative attitudes towards minorities depends on the group in question. For example, Creighton and Jamal (2015) consider public opinion about the offer of citizenship to immigrant groups which are defined by religious affiliation and find no significant evidence that opposition towards Muslim immigrants is masked in the United States. Instead, their results suggest that opposition towards immigrants who match the religious practice of the majority in the host population (e.g. Christians in the US), is substantively and significantly masked. In contrast, immigrant groups that are not co-religionists with the majority (e.g. Muslims in the US) are not subject to any significant social desirability pressure to appear tolerant. Preliminary evidence in the UK comes to similar conclusions (Creighton et al., 2016). The case of Ireland is largely unknown. There is no existing quantitative evidence of social desirability bias in Ireland. However, qualitative research suggests that at least some segments of Irish society tend to mask or conceal negative attitudes towards immigrants and immigration. Byrne (2014) used 
unstructured interviews to study attitudes towards immigrants and immigration among Irish professionals. The study uncovered negative attitudes among this group but found that the expression of these views is often limited to the private sphere. It argues that these professionals tend to distance themselves from immigration, by claiming ignorance about the subject. It also highlights 'ethnic hierarchies' among professionals, whereby newcomers from a lower socio-economic background are problematised on the basis of a perceived threat to the Irish economy.

Immigration tends to overlap with racial, ethnic and religious diversity. Multiple studies have shown that opposition to people on the basis of all of these attributes is also subject to masking. Using a variety of techniques ranging from the extension of anonymity to respondents to the use of implicit association tests, the literature has consistently found that race-based intolerance is under-reported (Kuklinski et al., 1997a; 1997b; Kuppens and Spears, 2014; Heerwig and McCabe, 2009). These results further indicate that measures of openly expressed (in)tolerance towards ethnic or racial out-groups are potentially subject to pressure to report greater tolerance than actually prevails when opinions are expressed implicitly or anonymously.

In addition, some evidence suggests that masking varies by the characteristics of the respondent. In particular, Janus (2010) used a list experiment to study the effect of respondent education on social desirability among non-Hispanic White Americans who are asked about a policy to restrict immigration. He found that people with college degrees were more likely than any other group to mask. However, this was only true of people who finished their education after their primary degree. People with post-graduate degrees were generally quite positive about immigration when asked directly, and it emerged that this was not due to social desirability bias. Other work, by Bazo-Vienrich and Creighton (2018) found that the difference between openly and anonymously expressed support for a closed border in the US varies significantly by the racial and ethnic identity of the respondent.

This report is the first quantitative study to consider the extent to which social desirability is unevenly distributed across multiple socio-demographic characteristics in Ireland. We consider age, gender, educational attainment and levels of financial stress. This is the first step in evaluating whether the relationships between attitudes to diversity and these 
covariates - which emerge from survey data - hold when attitudes are measured anonymously.

Overall, it is increasingly clear that standard efforts to measure anti-immigrant sentiment can systematically underestimate the prevalence of opposition. Although targeted opposition to some immigrant groups (e.g. Muslims) has been found to be less socially undesirable, many other minority attributes, in particular race, do elicit masking. Whether considering immigration in general, certain immigrant groups, or the intersection of immigration and race/ethnicity, efforts to measure the pattern and prevalence of antiimmigrant attitudes needs to accurately account for the challenges posed by querying sensitive information.

Social desirability bias exists in concert with other mechanisms that can undermine the effectiveness of standard survey questions. Another source of bias is determined by the extent to which a topic is considered intrusive, which is rooted in social and cultural context. Examples are sexual behaviour, medical history and religiosity. This is distinct from social desirability bias in that the attribute might not be perceived to be undesirable, but instead, is considered inappropriate to express under the conditions a survey offers - regardless of the mode of collection. As pointed out by some (e.g. Krumpal, 2013), this form of bias is focused on the sensitivity of the question rather than the response (Fowler, 1995). A second, related mechanism accounts for the costs of disclosure. For example, admitting to criminality, racism, sexism and homophobia can all incur social and legal consequences. The consequences need not be real, but simply the perception that there is any cost associated with telling the truth is enough to bias the responses to a given question. In the end whether the mechanism is social desirability bias (i.e. the masking of attitudes to meet contextual expectations), intrusiveness, or the cost of disclosure - the ability of respondents to feel that their responses are credibly and permanently guaranteed anonymity is crucial. 


\section{CHAPTER 3}

\section{Data collection and the list experiment}

\subsection{HOW THE DATA WERE GATHERED}

A strength of list experiments is that they can be carried out on nationally representative data gathered in standard surveys, including telephone surveys (Janus, 2010). The challenge is to avoid 'priming effects' by collecting the data as part of a survey that is not related to the sensitive issue, in this case attitudes to immigration. This list experiment, the first in Ireland, was fielded as part of the Economic Sentiment Monitor (ESM).

The ESM is a monthly telephone survey which collects information on people's views of the economic situation, the housing market and the savings environment in Ireland. The data are used to track changes over time in people's views and experiences. The survey provides data for the Consumer Sentiment Index, the Savings Index and input into macro-economic modelling. As well as assessing consumer sentiment, the monitor also collects demographic information from respondents such as their age, gender, family and marital status, education, nationality, employment status, occupation and whether the respondents are currently experiencing financial stress. An outline of the ESM survey questionnaire is presented in Appendix 2 for information.

The Economic Sentiment Monitor is a nationally representative survey carried out by the ESRI on a monthly basis, with a sample size of 800 respondents, and has been fielded since April 2008. A fresh national sample is used each month. Post-stratification is used to select the person to be interviewed in each household based on gender, age group and employment situation. The numbers required in each category are based on national figures from the Quarterly National Household Survey (now called the Labour Force Survey). ${ }^{9}$ Over time the survey methodology has been adapted to include households that only have a

9 In practice, this involves interviewers (once they make contact with a household) asking to speak, in particular, to someone in the 'difficult to reach' groups, such as men, younger adults and people with fulltime jobs. 
mobile telephone (see the appendix of Duffy et al. (2015) for further details of the sampling strategy).

Detailed response rates were compiled by Duffy et al. (2015) and these are indicative of more recent response rates. About 19 per cent of landlines initially selected by ESM interviewers were deemed eligible for interview (that is, they were in the age/gender/ economic status group for which the required number of interviews has not yet been completed).

Since September 2013, the survey has included a mobile-only sample. This sample is designed to complete a minimum of 125 interviews each month with people who have a mobile telephone but who do not have a landline in the home. This group has increased in size and is particularly important among young adults. For the mobile phone sample, there is an additional screening criterion in that the survey team seek to include only those who do not also have a landline in the home. On average in 2013, only 9 per cent of the contacted numbers ( 5 per cent of the numbers dialled) connect to a person who is eligible to be interviewed. Of the connected calls to a person known to be eligible, 52 per cent complete the interview. Combining the figures for the landline sample and the mobile sample, Duffy et al. (2015) estimate the response rate for the months in 2013 when both are included (i.e. from September onwards) is 53 per cent of the contacted numbers known to be eligible and 37 per cent when re-calculated to take account of the likely eligibility rate among the non-contacts. ${ }^{10}$

The data were re-weighted to be fully representative of the national population of adults at the time of the survey (June and July, 2017) using the Quarterly National Household Survey (QNHS). The weights include sex, age (eight categories), marital status, principal economic status, education, region (Dublin, Border, Midlands, West and the rest of the country) and number of adults over 18 in the household. A further weighting of the list experiments was

10 A large majority of the non-respondents are refusals. There are also numbers where no contact was made. In calculating an overall response rate, an assumption needs to be made about whether or not these numbers are valid household numbers. If we assume that the eligibility rate is the same among the noncontacted numbers as among those where eligibility has been determined, 37 per cent is the estimated response rate. 
carried out to harmonise between the treatment and control groups, this adjustment was weighted by sex and four age groups.

The list experiment was inserted in a separate section entitled 'Opinions on different issues', between a group of questions on personal savings and the background questions. The treatment group were read out a list with the sensitive item, and the control group were read a list without the sensitive item followed by the direct question (for detailed question wording see Section 3.2 below and also Appendix 2).

\subsection{THE LIST EXPERIMENT}

\subsubsection{An introduction to the list experiment}

It is not easy to elicit candid responses to sensitive questions. In fact, significant bias in responses to surveys that target controversial topics has been pointed out for more than four decades (Phillips and Clancy, 1972; Jackman and Muha, 1984; Holbrook and Krosnick, 2010; Glynn, 2013; Krumpal, 2013). One approach to elicit more honest answers to controversial questions is to provide anonymity. Some efforts to increase anonymity focus on the mode of interaction, considering more indirect interactions to yield more candid answers (e.g. phone vs. online vs. in person). However, regardless of the mode of interaction, anonymity is not fully guaranteed if the question is posed directly to the respondent.

Others seek to alleviate bias by considering sub-conscious/unconscious mechanisms. For instance, the Implicit Association Test (IAT) can be used to measure the time it takes a respondent to sort members of in-groups and out-groups into positive and negative categories. Relative delays in sorting members of out-groups into positive categories and vice versa are used as measures of sub-conscious intolerance. A drawback of the IAT is that the results cannot be compared to standard surveys or public opinion polls. Furthermore, because it attempts to measure implicit bias, it only targets sentiment which is unintentionally masked.

Measuring attitudes that are intentionally masked requires a third approach, termed the list experiment, which uses permanent and guaranteed anonymity to avoid the possibility of identifying an individual response. This alleviates the social pressure to mask controversial 
attitudes without losing direct comparability with standard measures of public opinion. In brief, the list experiment offers a reasonable method to assess negative sentiment towards minority groups because it (1) guarantees absolute and permanent anonymity, (2) is easily implemented with a representative sample and (3) is directly comparable with measures used in standard survey data.

The list experiment works by presenting respondents with a list of items, and by asking how many of them they agree with. Crucially, they are not asked which of the items they agree or disagree with. A control sample is given a list of three items, covering topics like assistance to the poor, taxation and environmental regulation. A treatment group is presented this same list, but with the addition of a focal item that asks about support for the controversial topic of interest - more Muslim or Black people coming to Ireland in this case. Interviewers were instructed to randomly assign respondents to the treatment and control groups. Because both samples are presented the same control list items, any difference between the average response to the control and treatment is due to the additional (focal) item. At the group level, simply subtracting the average response to the control from the average response to the treatment offers a way to ascertain support for the focal item (i.e. support for Muslim or Black immigration) under conditions of anonymity.

The key to the success of the list experiment is that respondents are never asked to articulate support for any specific item in the list, which guarantees permanent anonymity from the interviewer at the individual level. ${ }^{11}$ An additional step, which is taken in this experiment, is to ask the control group to directly express their support for Black immigration (June ESM) or Muslim immigration (July ESM) in the absence of absolute, permanent anonymity. This is done via a standard survey question. The difference between directly expressed and anonymously expressed support is interpretable as a measure of the extent to which support for Black or Muslim immigration is over-stated. In addition, variation in the extent to which masking of intolerance occurs can be observed by

11 Unlike temporary anonymity, where an individual's opinion is recorded and subsequently redacted, under conditions of permanent anonymity the person's opinion, such that it can be attributed to them, is not recorded. The survey interviewer never knows which of the items on the list the respondent supports. 
subgroups of the population (e.g. men and women, different age groups, people with different levels of education), though not for any individual respondent.

\subsubsection{Application of the list experiment in Ireland}

The list experiment is specifically designed to manipulate the amount of anonymity guaranteed to respondents. As with any experiment, the basic design involves independent samples designated as treatment and control groups (see Figure 3.1). In this case two control samples were used that correspond to two distinct periods of fieldwork - June and July.

\section{FIGURE $3.1 \quad$ LIST EXPERIMENT DESIGN}

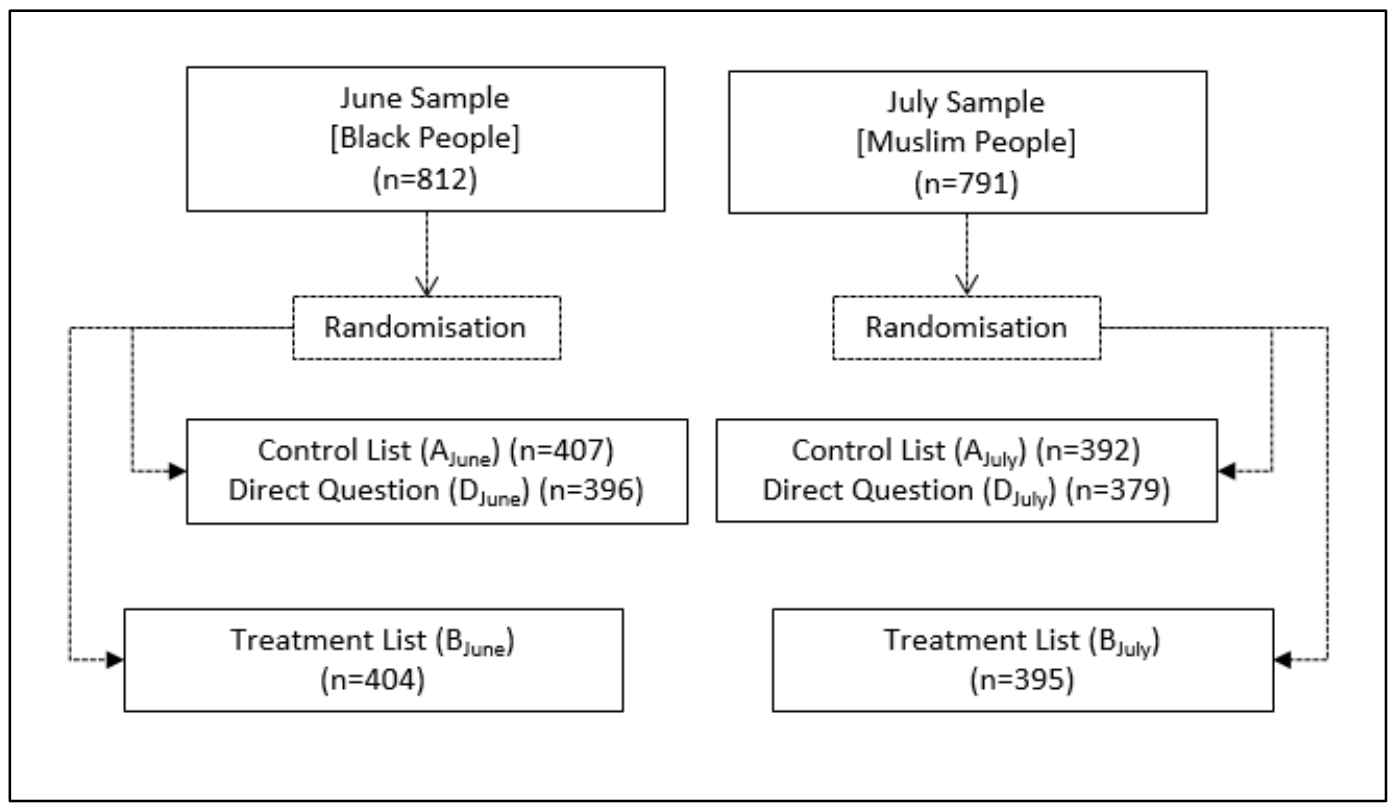

Each independent control sample was presented with the following list question:

(A [June and July]) The next questions are about your opinion on a few different issues in Ireland today. I am going to read out three things that you may or may not support. After I read all three, just tell me HOW MANY of them you support. I don't want to know which statements, just HOW MANY.

- Higher weekly State Pension.

- Lower tax on diesel

- Bigger fines for litter

Responses range from zero to three. The distributions of responses for the two months of the survey is shown in Figure 3.2. The mean (average) responses for June 
and July were 2.24 and 2.15 respectively, which indicates that respondents supported slightly more than two items in the control list.

\section{FIGURE 3.2 LIST RESPONSES: CONTROL GROUP}

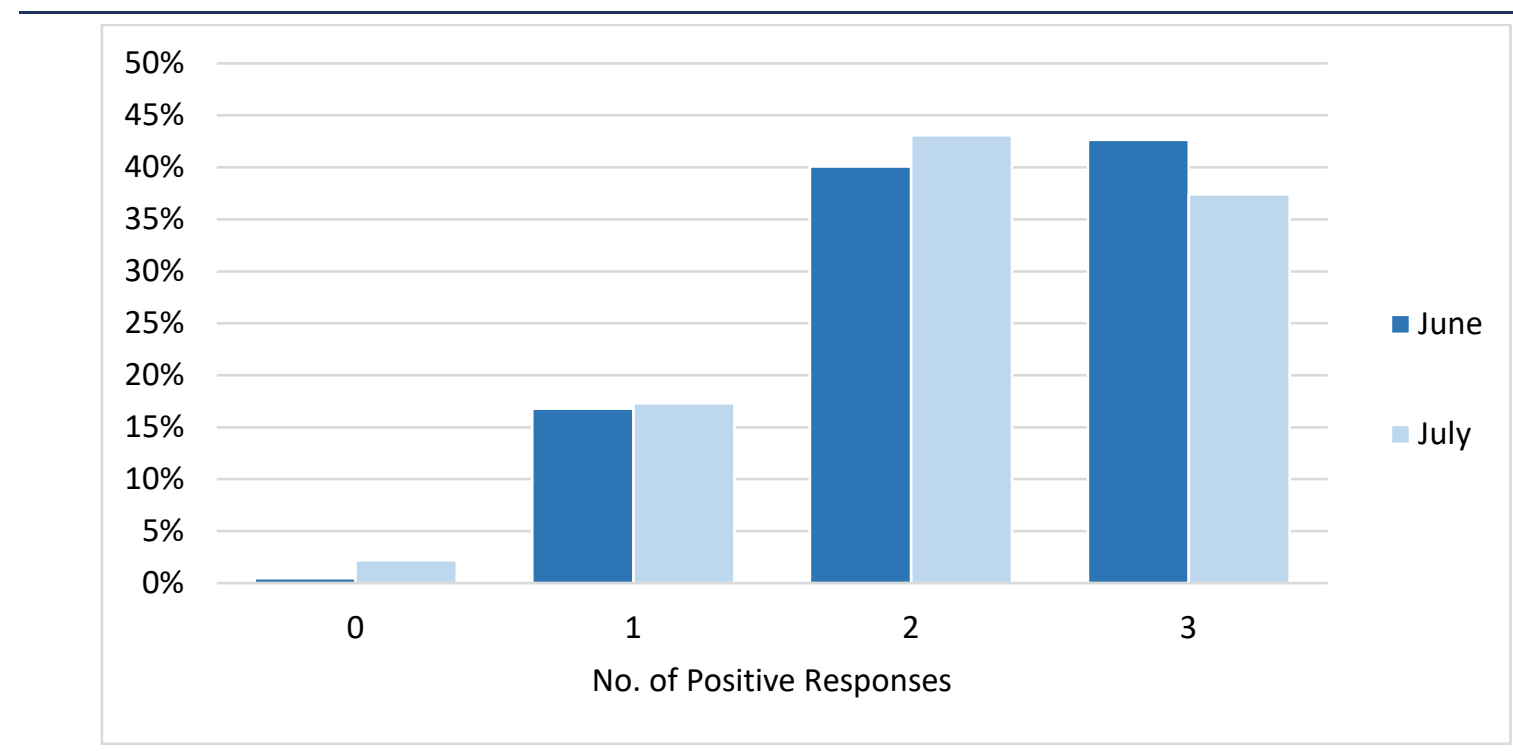

Two independent treatment groups were presented with an identical set of list items as the control samples, but with the following additional focal items included:

$\left(B_{\text {[June] }}\right)$ More Black people coming to live in Ireland

$\left(B_{[J u l y]}\right)$ More Muslim people coming to live in Ireland

\section{FIGURE 3.3 LIST RESPONSES: TREATMENT GROUP}

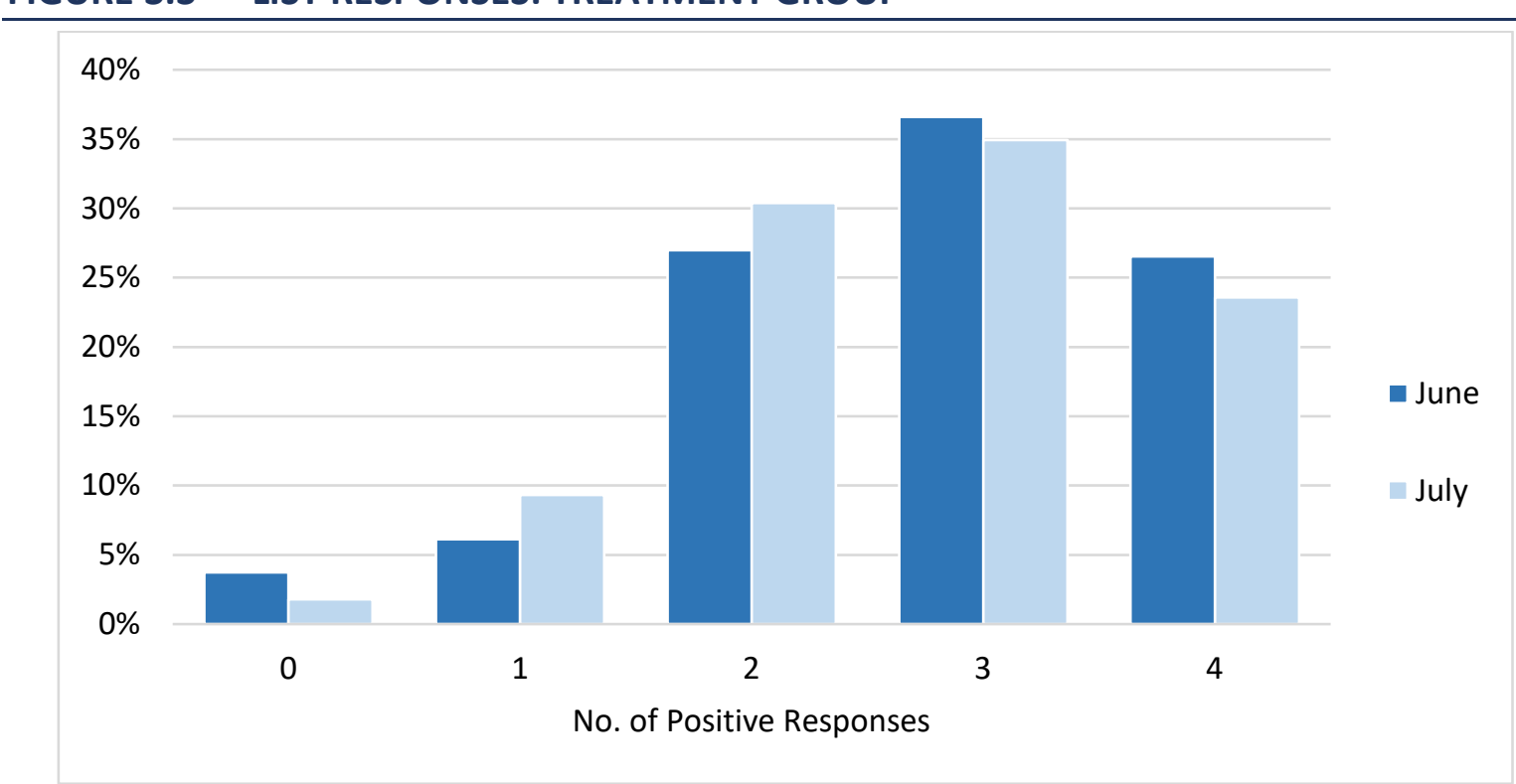


Responses to the treatment list questions range from zero to four. The breakdown of these responses is shown in Figure 3.3. The mean responses for June and July are higher than the control list, at 2.71 and 2.63 respectively.

The difference between the mean response to the control list question and that of the treatment list measures the proportion of respondents who support the additional focal item (i.e. Black or Muslim immigration). This difference is the proportion of the Irish population that express support for more Black or Muslim immigration under conditions of anonymity, which is referred to as anonymously expressed support. One advantage of this design is that anonymously expressed support can be compared to support expressed without the guarantee of permanent and absolute anonymity, which is referred to as directly expressed support. Directly expressed support is captured by the following two questions:

$\left(D_{\text {[June] }}\right)$ Would you support more Muslim people coming to live in Ireland?

$\left(D_{[J u l y]}\right)$ Would you support more Black people coming to live in Ireland?

The resulting data give us a broader picture of support for the immigration of certain groups in Ireland. Directly expressed support offers insight into attitudes which are comparable to a standard survey of public opinion. Comparing this to anonymously expressed support allows us to discern the way in which support changes depending on the extent to which respondents are afforded the ability to mask their response.

A more detailed, technical description of the list experiment methodology is provided in Appendix 1. 



\section{CHAPTER 4}

\section{Attitudes to Black and Muslim immigration to Ireland: Revealed and hidden}

We seek to present three statistics throughout this chapter:

- $\quad$ the percentage of people expressing positive attitudes to Black and Muslim immigration openly through the direct question on the survey;

- the percentage of people expressing these opinions anonymously via the list experiment;

- $\quad$ the difference between the two, which is our measure of social desirability bias.

We calculate these statistics both for the full sample of approximately 1,600 individuals, and for sub-samples which are broken down by gender, age, educational attainment and whether or not the respondent reports experiencing financial stress. These factors were chosen because they frequently emerge as significant predictors of attitudes to minority groups in research using survey data (e.g. McGinnity et al., 2018a; Ceobanu and Escandell, 2010; Hainmueller and Hiscox, 2007). Details on the breakdown of these characteristics in our sample are provided in Figure 4.1. 
FIGURE 4.1 SAMPLE CHARACTERISTICS, ESM JUNE AND JULY 2017

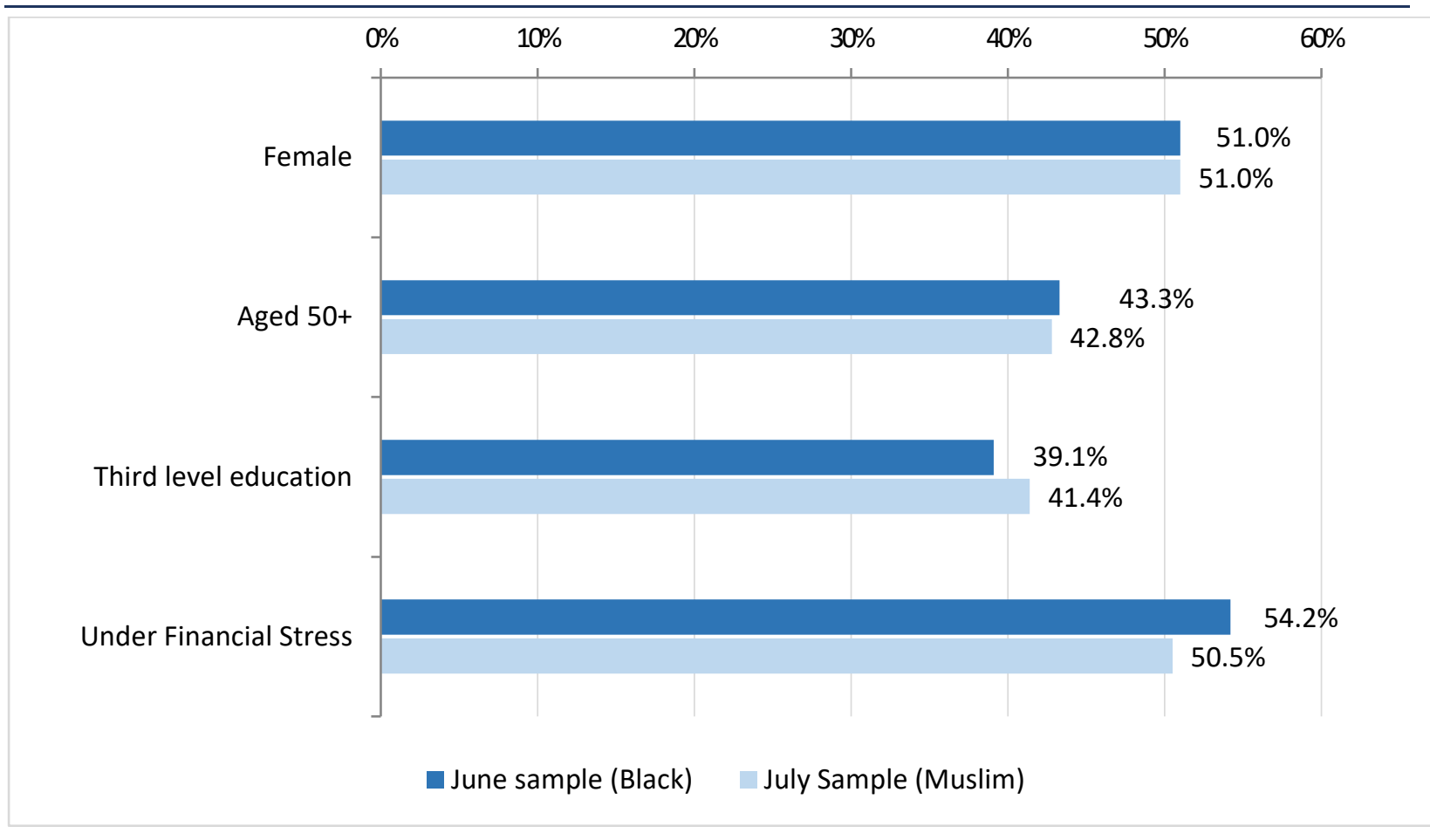

Source:

Own calculations based on Economic Sentiment Monitor, June and July 2017.

The groups have been divided so that no single group comprises less than 35 per cent of the sample. This is why an age cut-off of 50 years was selected. We consider people with a higher education certificate/diploma, a primary degree or a post-graduate qualification to have third-level educational attainment. Financial stress is measured by asking the respondent how difficult it is for them to 'make ends meet'. We consider people who report making ends meet 'with great difficulty', 'with difficulty' or 'with some difficulty' to be under financial stress. The data are weighted to ensure that they are representative of the population.

We present our results through a series of colour coded charts. Attitudes to the Black group are displayed in blue, and attitudes to the Muslim group are shown in yellow. The lighter shades show the openly expressed measure, which is the proportion responding positively to the direct question posed to the control groups. The darker shades of blue and yellow represent the anonymously expressed measure, which is calculated by measuring the difference between the mean scores on the lists for the control and treatment groups.

Our measure of social desirability is captured by the vertical arrows in each graph. Where they are statistically significant, they are displayed as the percentage point difference 
between the directly and anonymously expressed measures. ${ }^{12}$ Alternatively, these can be interpreted as the percentage of the relevant sample who 'mask' - i.e. who hold negative attitudes but choose not to reveal them to the survey interviewer. Throughout, we refer to respondents 'holding but concealing' negative attitudes or lack of support. Here we explicitly mean that they conceal them from the interviewer. We cannot tell how likely it is that they would conceal them in other settings. The charts in this chapter are based on the full sample, but we report results using a slightly smaller sample which excludes 74 non-Irish respondents, where these findings differ from those using the full sample.

\subsection{ATTITUDES TO BLACK AND MUSLIM IMMIGRATION}

Figure 4.2 shows the results for the full samples from both months of the survey. We first consider what proportion of the samples said they would support more Black or Muslim people coming to Ireland. The percentage of people who favour more Black people coming to Ireland, which stands at 66 per cent, is the only recent estimate of its kind. Support for more Muslims coming to Ireland is lower, at 59 per cent. However, this figure is higher than previous estimates. According to the 2014 European Social Survey, which is the most comparable dataset we have, 11 per cent of the Irish-born population said that 'many' Muslims should be allowed to come in Ireland, 30 per cent favoured allowing 'some', 34 per cent would allow 'a few' to come and a quarter said that none should be allowed to come. Here of course, the question format is significantly different, because the control group is asked a binary yes/no question. Furthermore, the question is specifically about support for inward migration of these groups. As there is no option to express 'neutral' opinions about Black and Muslim immigration, that is 'don't know' or 'don't mind either way', we cannot interpret a lack of support as opposition towards these groups. However, we do not expect this to alter the pattern of results.

Next, we consider the anonymously expressed scores, and their distance from the direct measures, which we interpret as an indicator of social desirability or masking. We find that the gap between attitudes to the Black ethnic group and attitudes to the Muslim group is

12 We determine a finding to be statistically significant if the observed difference between overt and anonymously expressed scores is highly unlikely (less than 10 per cent) to be a result of chance. The probability that a finding is a result of chance is called a ' $p$-value'. 
almost entirely due to different rates of social desirability on each item. When we give the respondent the opportunity to conceal their views within the list, attitudes towards the two groups level out at 51 per cent for Black people and 53 per cent for Muslims.

Respondents in Ireland are much more likely to overstate support for the Black ethnic group than for the Muslim group. Anonymity reduces the prevalence of positive attitudes to the Black ethnic group by 15 percentage points, and attitudes to the Muslim group by six points, but the latter is not statistically significant.

\section{FIGURE 4.2 SUPPORT FOR BLACK AND MUSLIM PEOPLE COMING TO IRELAND}

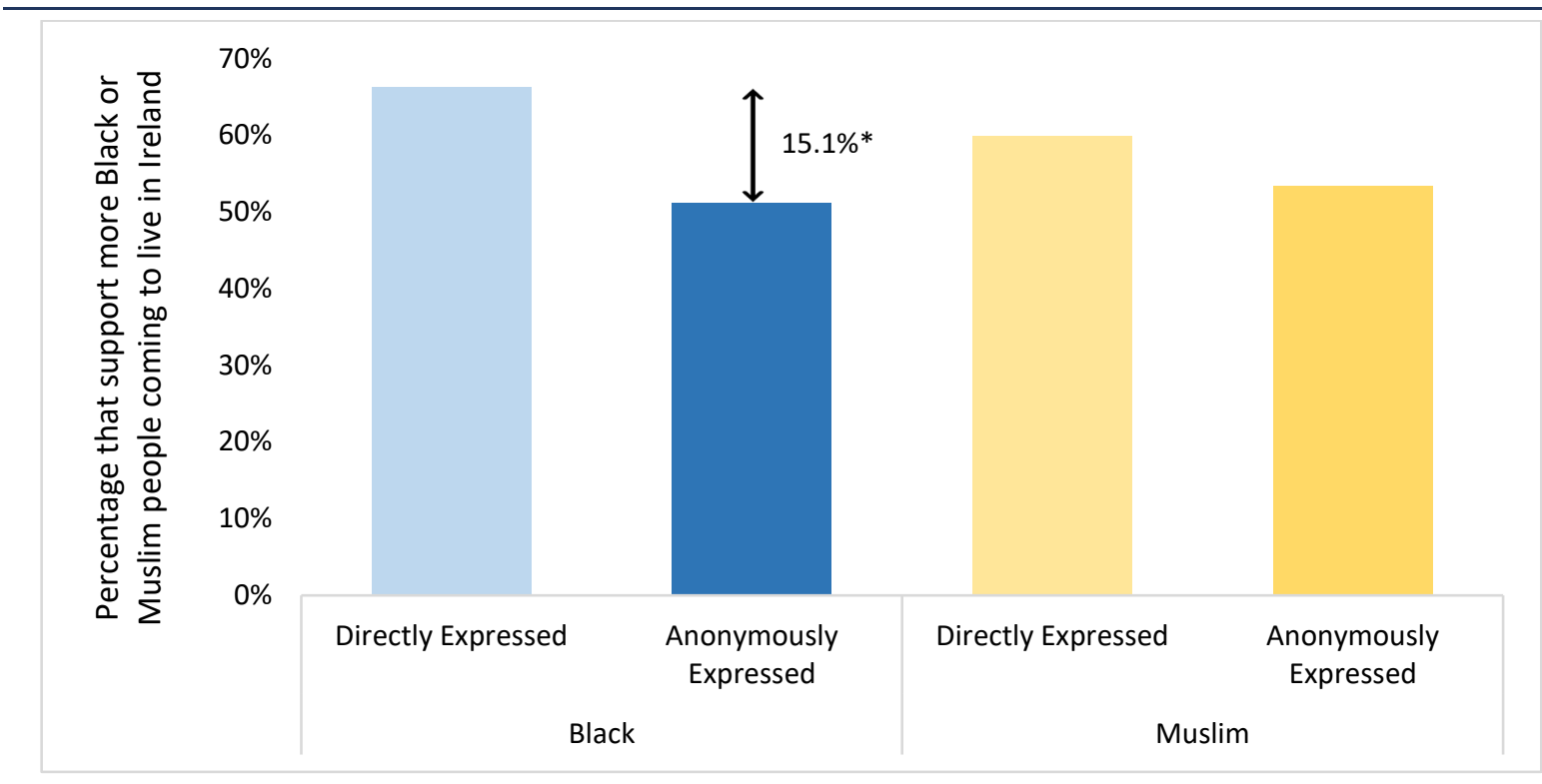

Source: $\quad$ Own calculations based on Economic Sentiment Monitor, June and July 2017.

Note: $\quad$ The arrow indicates statistically significant masking or social desirability bias. * indicates $p<0.05$. Data are weighted.

Anonymously expressed support for various groups is difficult to compare internationally as there are no list experiments with precisely the same wording, and responses are very sensitive to question wording, as is the extent of socially desirability bias in those responses. The closest example is a series of similar experiments in the UK, which considered openly and anonymously expressed attitudes to Muslim and Black Caribbean immigration. These list experiments were embedded in two waves of Understanding Society's Innovation Panel (IP) in 2015 and 2016. Comparing the results, we see that both directly and anonymously expressed attitudes appear to be more positive in Ireland. For instance, in each wave of the IP panel, overt support for Caribbean immigration was only 60 per cent, compared to 66 per cent support for Black immigration in Ireland. Overt support was also a good deal lower in the UK, at 30 per cent in the first experiment and 42 per cent in the second 
(Creighton et al., 2016; Benzeval et al., 2017). Of course, these groups are not entirely comparable, not least because very little immigration of Black people in Ireland is from the Caribbean. However, a similar pattern of results emerges for attitudes to Muslim immigration. Between 40 and 49 per cent of UK respondents openly expressed support for Muslim immigration, compared 60 per cent in Ireland. The anonymously expressed support for Muslim immigration was also lower in the UK, at between 30 and 36 per cent second (Creighton et al., 2016; Benzeval et al., 2017).

In a Dutch survey experiment in 2014, 62 per cent of respondents supported the statement that the Netherlands should allow more people of the same ethic group when directly expressed, but only 19 per cent of respondents supported this when anonymously expressed. A similar proportion (62 per cent) supported immigrants of the different race coming to the Netherlands, but this compares to 40 per cent of the sample who anonymously expressed support for people of a different race coming to the Netherlands. This anonymously expressed support for immigrants of a different race coming to the Netherlands is lower than anonymously expressed support for more Black people coming to Ireland in Figure 4.2 (51 per cent). However, the question wording is rather different in the two experiments, so they are not directly comparable.

The findings suggest that people in Ireland who hold negative attitudes towards Muslim immigration consider it acceptable to honestly express those attitudes, but that survey respondents feel the need to conceal negative attitudes towards Black immigration. In the absence of other list experiments in Ireland, it is not clear whether this pattern can be explained by particularly high levels of social desirability bias in the responses to the question about Black immigration, or particularly low levels in the responses to the Muslim immigration question.

That said, the results are consistent with a growing body of international scholarship which finds that attitudes towards Muslim immigrants and immigration are less sensitive to masking. For instance, Creighton and Jamal's (2015) study of granting citizenship to Muslim and Christian immigrants in the United States shows that respondents conceal a considerable amount of resistance to Christian immigrants, but Muslim immigrants are afforded no such protection. The aforementioned work using list experiments in the UK 
shows less masking of opposition to Muslim immigrants, relative to immigrants from Eastern Europe and the Caribbean (Creighton et al., 2016; Benzeval et al., 2017).

One explanation for this variation may be that religion, unlike race, is viewed as a choice. Another could be a belief that Islam is incompatible with the norms of Western society and can therefore be justifiably rejected. Storm (2018) argues that hostility towards immigrants in Europe stems from notions of non-conformity with the host country. In her analysis, survey respondents who adhere to the majority religious denomination are more likely to view immigration negatively, while members of minority religious groups are significantly more positive.

The following discussion is motivated by the question of whether attitudes and masking of socially undesirable opinions vary across the population. The analysis is repeated for different groups in the population and reveals interesting patterns. Social desirability bias varies according to age, sex and educational attainment. Some of these relationships also vary depending on whether the questions relate to Black or Muslim immigration.

\subsection{GENDER AND ATTITUDES}

Figure 4.3 shows the breakdown by gender. We find that men are more positive to Black immigration than women are on the direct measure, but this gender difference disappears when we focus on the anonymously expressed scores. About 72 per cent of men state directly that they would support more Black people coming to Ireland, compared to just 61 per cent of women. Men and women show identical anonymously expressed attitudes to Black people -51 per cent of each are positive.

Regarding support for the Black ethnic group, social desirability affects 21 per cent of men in the sample, but less than 10 per cent of the women in the sample. The gender difference in openly expressed attitudes is thus 'washed out' by social desirability bias. 
FIGURE 4.3 GENDER DIFFERENCES IN SUPPORT FOR MORE BLACK AND MUSLIM PEOPLE COMING TO IRELAND

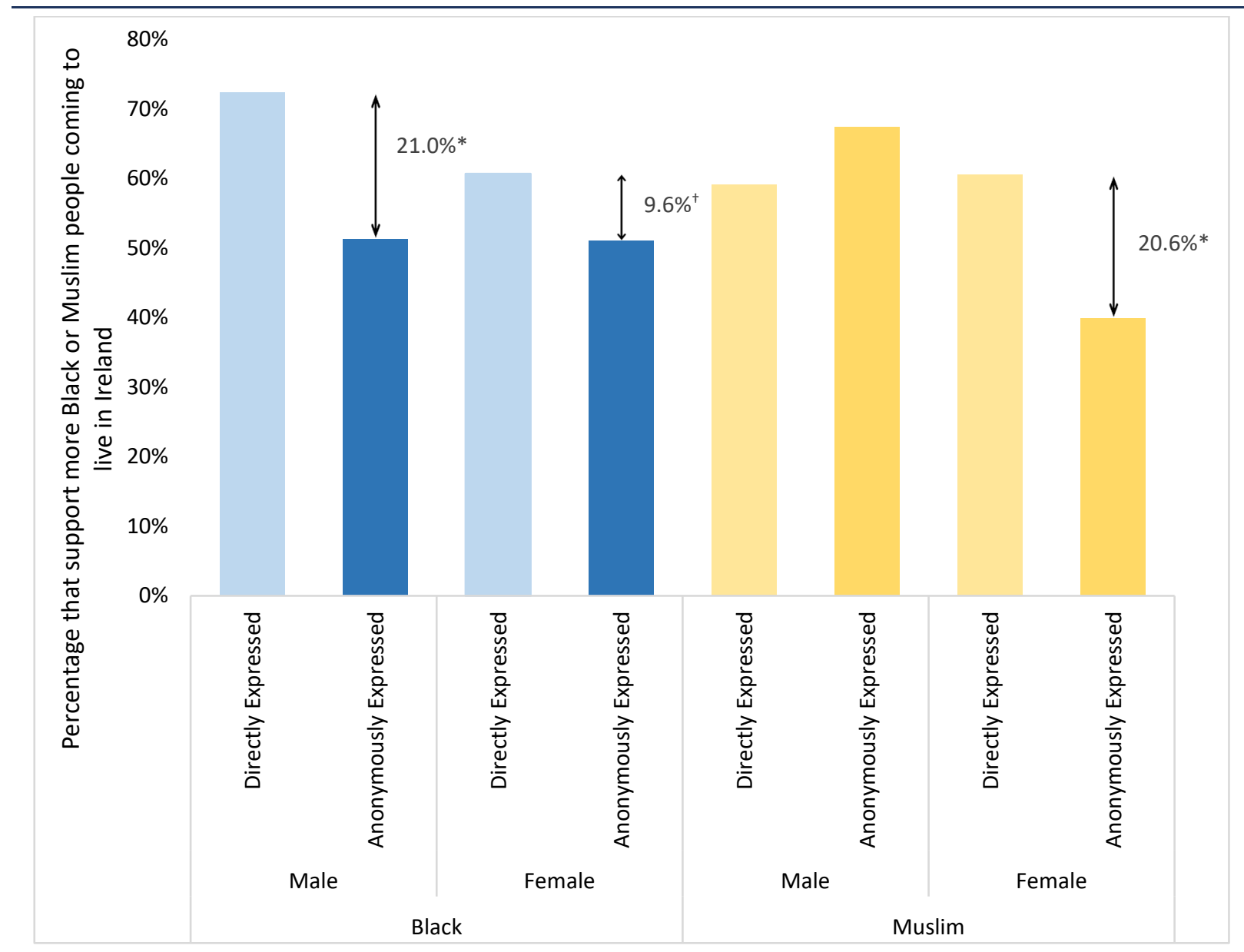

Source: Own calculations based on Economic Sentiment Monitor, June and July 2017.

Notes: $\quad$ Arrows indicate statistically significant masking or social desirability bias. + indicates $p .<0.1$ and $*$ indicates $p<0.05$. Data are weighted. While the anonymously expressed score on attitudes towards Muslims appears to be higher than the directly expressed score among men, this difference is not statistically significant.

The relationship between gender and social desirability is reversed when support for more Muslim people coming to Ireland is the topic of the question. For men, 59 per cent support more Muslims coming to Ireland in the direct question and 67 per cent support more Muslims coming to Ireland when anonymously expressed, though this difference is not statistically significant.

For women, 61 per cent support more Muslim people coming to Ireland when asked directly, but only 40 per cent of women do when asked anonymously. Thus, over one-fifth of this sample of women 'overstate' their support for Muslims. They do not actually support more Muslim people coming to Ireland but choose not to reveal this to the interviewer. 
The intersection of multiple embedded and overlapping negative perceptions of Muslims may contribute to what Helbling and Traunmüller (2018) label 'double opposition' towards this group. On the one hand, some people are opposed to immigration in general, that is more of any group coming to their country. On the other, some who have little issue with immigration in general take exception to perceptions of incompatible cultural norms relating to gender and sexuality among Muslims.

\subsection{AGE AND ATTITUDES}

Figure 4.4 displays the results by age categories. We split the sample in two, with one group aged $16-49$ and the other aged 50 or older. ${ }^{13}$ The expected relationship between age and tolerance, whereby younger people express more positive attitudes to ethnic and religious minorities, is borne out by the results on the direct survey item. Support for the Black ethnic group among the younger respondents (aged under 50), at 78 per cent, is 27 percentage points higher than support among older people (those aged 50 and over). On the question about Muslims, there is less of an age gradient, but the under 50s still score over 10 percentage points higher (almost 65 per cent) than those over 50 (53 per cent).

When anonymously expressed results are considered, this age difference is smaller. Regarding more Black people coming to Ireland, 59 per cent of those under 50 are supportive, compared to 40 per cent of those aged 50 or over. Regarding support for Muslims, the age difference disappears: 54 per cent of the younger group (aged under 50) and 53 per cent of the older group (aged 50 and over) are supportive of more Muslim people coming to Ireland (see Figure 4.4).

This suggests that those aged 50 and over are somewhat less likely to mask negative opinions than those aged under 50 . Only 11 per cent of those aged 50 and over mask their negative opinions when asked about the Black ethnic group, compared to nearly 19 per cent of those aged under $50 .{ }^{14}$ There is no evidence of people aged 50 and older masking

13 Given the sample size, it was only possible to consider two age groups, but note that these age bands are very wide, and any reference to 'younger' and 'older' in this experiment refers simply to 'under 50' and ' 50 and older' respectively.

14 In fact, if we exclude non-Irish respondents from the sample, masking among those 50 and over drops to 9.6 per cent and becomes statistically insignificant. 
negative attitudes towards Muslims, while the data suggest that over 10 per cent of people under 50 mask their true preferences on this issue. ${ }^{15}$

FIGURE 4.4 AGE (UNDER 50/50+) AND SUPPORT FOR MORE BLACK AND MUSLIM PEOPLE COMING TO IRELAND

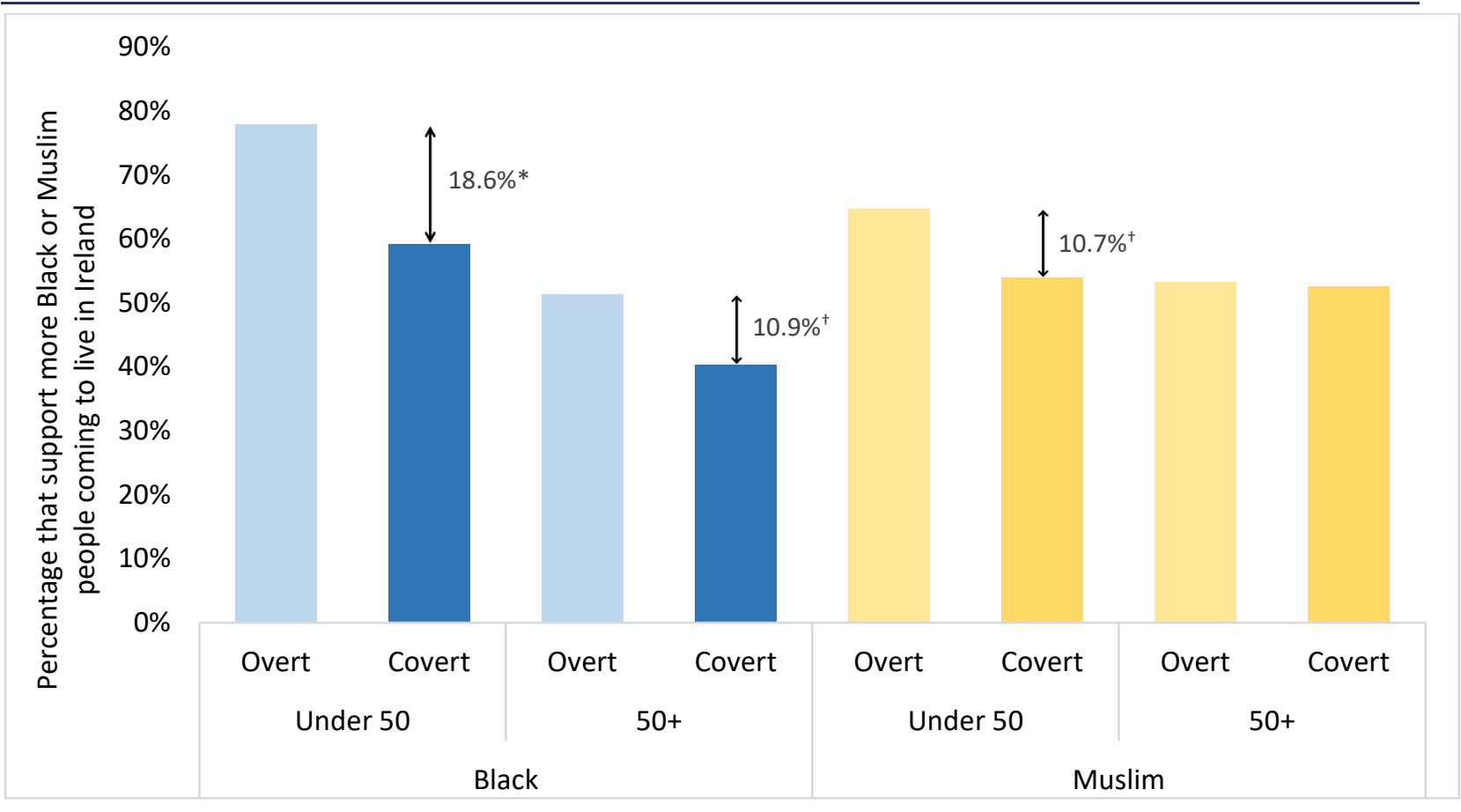

Source: $\quad$ Own calculations based on Economic Sentiment Monitor, June and July 2017.

Notes: $\quad$ The younger category is comprised of respondents aged 16-49 and the older category is comprised of respondents aged 50 or older. Arrows indicate statistically significant masking or social desirability bias. tindicates p. $<0.1$ and $*$ indicates $p<0.05$. Data are weighted.

The finding that there is no age difference in anonymously expressed attitudes to Muslims is interesting, because age is typically viewed as a robust and consistent predictor of these attitudes in the existing research using surveys with direct questions, albeit with much more fine-grained age categories (for example see Strabac and Listhaug, 2008, for comparative analysis; Fahey et al., 2019 for Ireland). ${ }^{16}$ That said, the age bands used in the list experiment are very wide: comparing attitudes of those under 30 with those over 65 , for example, would have been preferable but the sample size does not permit this.

15 That said, with a smaller sample excluding non-Irish respondents, the proportion of under 50s masking on this question drops to under 9 per cent and becomes statistically insignificant.

16 Strabac and Listhaug (2008) measure age in decades; Fahey et al. (2019) use four age categories: age under 25; 25-44; 45-64; 65+. Fahey et al. (2019) find a stepwise age pattern, with each older group being less supportive of Muslim immigration to Ireland than the previous group. 


\subsection{EDUCATION AND ATTITUDES}

An even more consistent finding in the literature on attitudes to diversity emerging from survey data is that higher educational attainment leads to more positive attitudes towards minority groups, in particular to immigrants (e.g. Coenders and Scheepers, 2003). However, there remains considerable debate on the causal mechanisms behind the effect. One school of thought focuses on the directly liberalising effect of education. Here it is argued that the very experience of attending a third-level educational institution exposes people to a more diverse set of ideas and people (Hainmueller and Hiscox, 2007). Another view concerns the fact that the highly educated tend to have more secure jobs and higher incomes than those with lower educational qualifications. The less educated are likely to be more directly in competition with immigrants for jobs and resources such as housing, services and social welfare (Mayda, 2006). Feeling threatened by immigrants, the less educated are more likely to express negativity towards them in attitudinal surveys. A third view, which is supported by these findings, is that people with higher educational attainment do not in fact hold more positive attitudes but are more likely to conceal negativity when asked a direct question in a survey.

Figure 4.5 shows that the highly educated, who are defined as having a third-level qualification (diploma, degree or higher), are more likely to openly express support for both groups when asked a direct question. Over four in every five respondents with a third-level qualification ( 81 per cent) say that more Black people should be allowed to come and live in Ireland, compared to just 57 per cent of those without a third-level qualification. A similar pattern emerges for the question about more Muslims coming to Ireland, but the difference is less pronounced. Sixty-seven per cent of the highly educated and 55 per cent of the less educated openly say that they would support more Muslim people coming to Ireland.

However, looking at the anonymously expressed measure, we find that these relationships disappear. Now we find 49 per cent of those without a third-level qualification supporting more Black people coming to Ireland, compared to 54 per cent of those with a third-level qualification (see Figure 4.5). Fifty-nine per cent of those without a third-level qualification and 45 per cent of those with a third-level qualification support more Muslim people coming to Ireland. Neither of these differences are statistically significant. 
Figure 4.5 shows that social desirability is highly concentrated in the most educated groups. While there is some evidence of masking among the less educated with respect to Black immigration (8.5 per cent) ${ }^{17}$ this pales in comparison to the highly educated group, over a quarter of whom (26.8 per cent) hold but conceal negative attitudes. The difference is as large in the Muslim survey. No statistically significant masking occurs with the less educated, but over a fifth (21.6 per cent) of the highly educated sample mask their views regarding Muslims (see Figure 4.5).

\section{FIGURE 4.5 EDUCATIONAL ATTAINMENT AND SUPPORT FOR MORE BLACK AND MUSLIM PEOPLE COMING TO IRELAND}

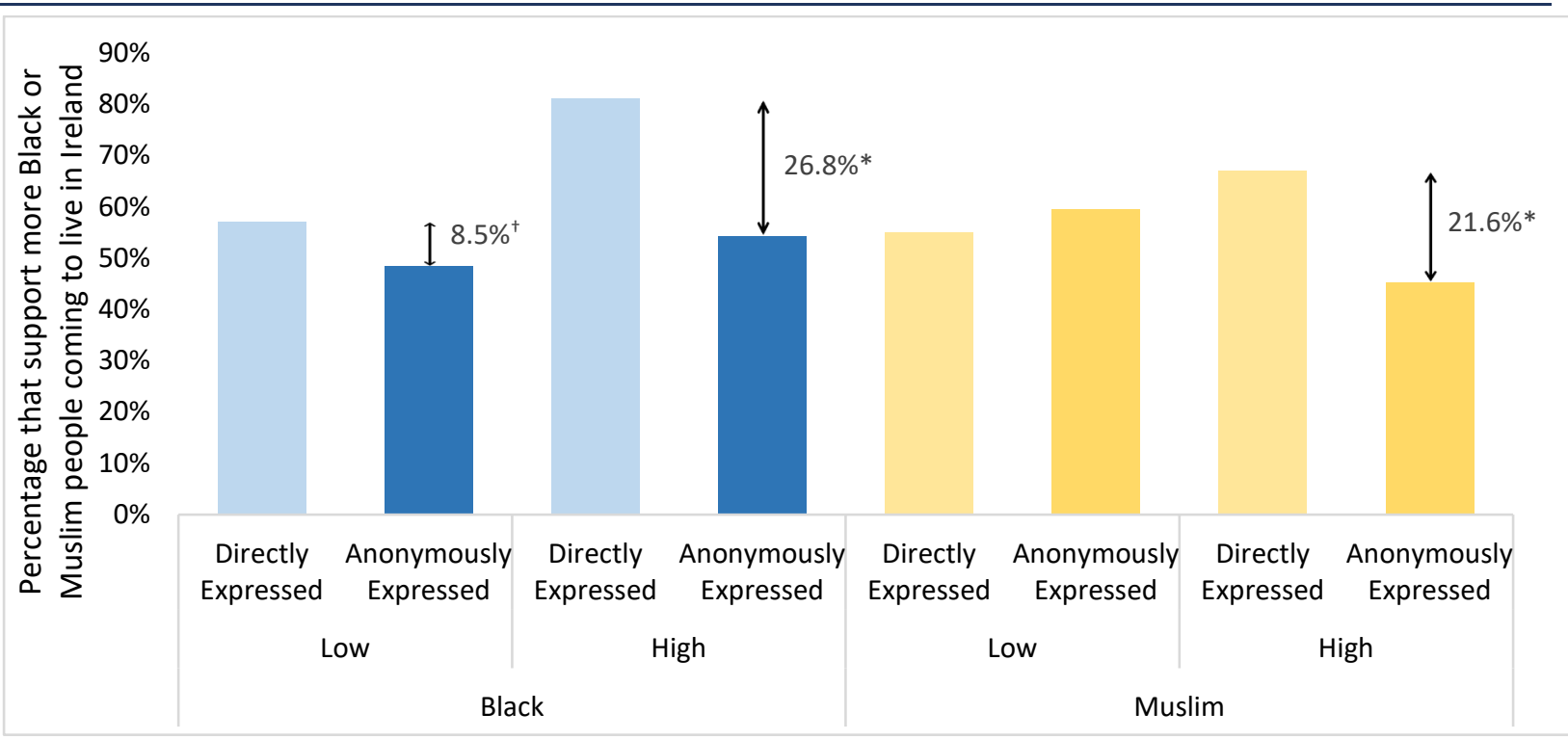

Source: $\quad$ Own calculations based on Economic Sentiment Monitor, June and July 2017.

Note: $\quad$ The lower educated group is comprised of respondents whose highest level of educational attainment is technical or vocational schooling, Leaving Certificate or lower. People with post-secondary education - higher diplomas, degrees or postgraduate qualifications - are counted as highly educated. Arrow indicates statistically significant masking or social desirability bias. $\dagger$ indicates p. $<0.1$ and ${ }^{*}$ indicates $p<0.05$. Data are weighted. While the anonymously expressed score on attitudes towards Muslims appears to be higher than the directly expressed score among the less educated, this difference is not statistically significant.

The findings about the extent of social desirability bias in attitudes to Black and Muslim immigration among the highly educated is particularly noteworthy given that those with decision-making power over the allocation of resources like jobs and housing tend to have higher education.

The results are also consistent with Byrne's (2014) findings on 'performing distance'.

17 Masking on this question rises to 11.4 per cent among the less educated when non-Irish respondents are excluded. 
Following qualitative interviews and participant observation among highly educated Irish professionals, she concludes that there is considerable resistance to immigrants and immigration among this group in Ireland, but this is carefully concealed using a variety of strategies, such as claiming ignorance in the topic of immigration and rationalising antiimmigrant sentiment in terms of economic threat.

\subsection{FINANCIAL STRESS AND ATTITUDES}

McGinnity et al. (2018a) found that people under financial stress report more negative attitudes to immigrants in Ireland. Here we investigate whether there are differences in masking between those who do or do not experience financial stress. We deem an individual to be under financial stress if they report 'some difficulty', 'difficulty' or 'great difficulty' making ends meet.

When asked a direct question, Figure 4.6 shows that 71 per cent of those with low or no financial stress support more Black people coming to Ireland, compared to 62 per cent of those with difficulty making ends meet. Fifty-eight per cent of those with no financial stress support more Muslim people coming to Ireland, compared to 60 per cent of those with difficulty making ends meet. Comparing anonymously expressed support, we find 58 per cent of those with no financial stress and 46.6 per cent of those with difficulty making ends meet support more Black people coming to Ireland. Regarding more Muslim people coming to Ireland, 49 per cent of the group experiencing no financial stress are supportive, and 58 per cent of those experiencing financial stress are supportive.

Compared to the other sub-groups, financial stress appears not to be a major factor in explaining social desirability in this experiment. On the question of Black immigration, social desirability is comparable between the two groups, at 13.4 per cent and 15.6 per cent. In the question about Muslim immigration, there is some (weak) evidence of masking among the low financial stress group, but the effect is just outside the limits of statistical significance at the 10 per cent level $(p=0.105) .{ }^{18}$ 


\section{FIGURE 4.6 FINANCIAL STRESS AND SUPPORT FOR MORE BLACK AND MUSLIM PEOPLE COMING TO IRELAND}

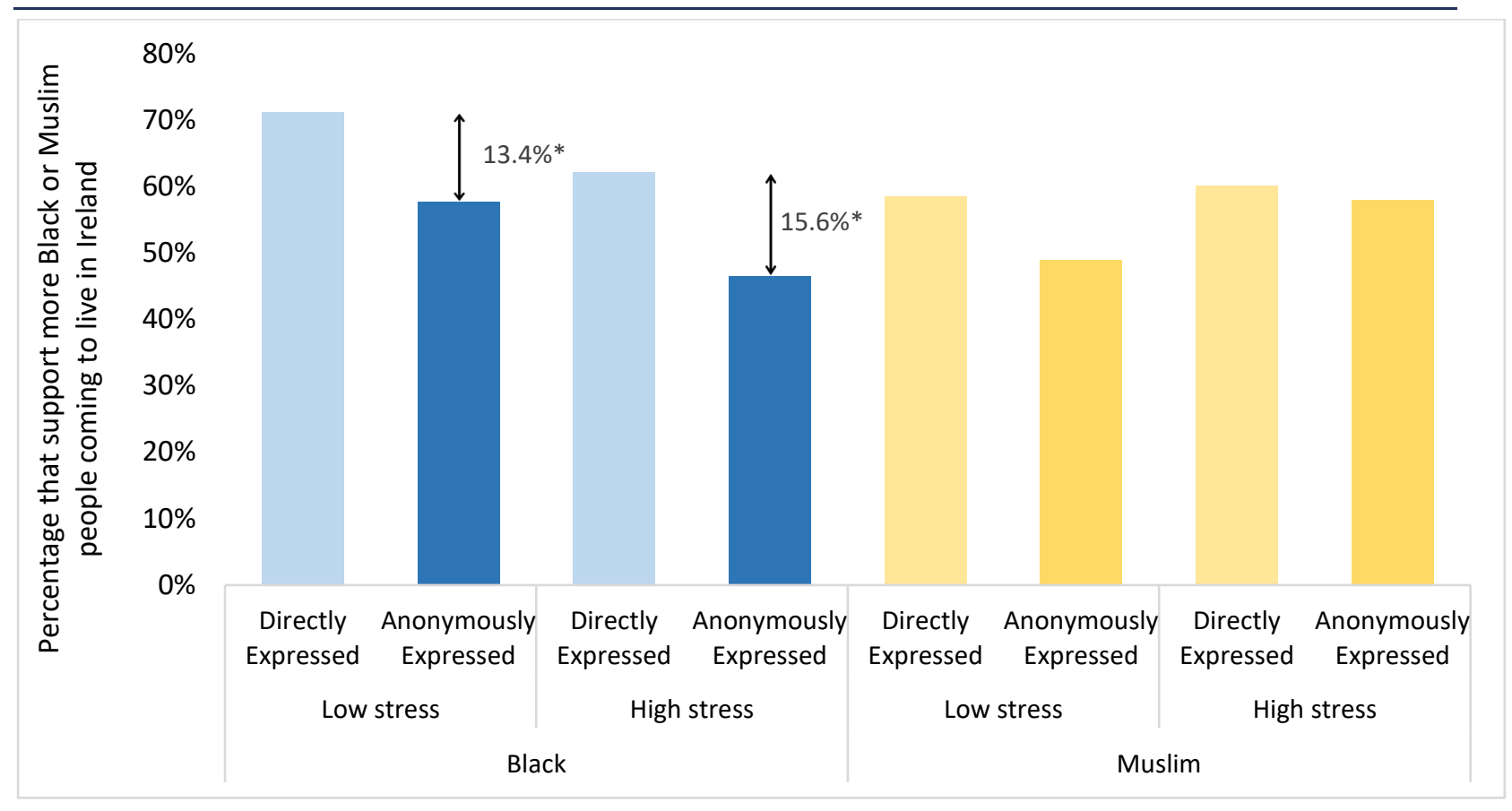

Source: Own calculations based on Economic Sentiment Monitor, June and July 2017.

Notes: $\quad$ Respondents who report making ends meet with some difficulty, with difficulty, or with great difficulty are counted as being under high financial stress. + indicates $p .<0.1$ and $*$ indicates $p<0.05$. Data are weighted.

The survey did not record whether respondents themselves were born outside Ireland, but a small number of respondents reported a nationality other than Irish. There were not enough of this group to explore the differences between Irish and non-Irish respondents in the experiment, but as a robustness check, we re-estimated all the analysis with a modified sample which excludes the 74 respondents who report non-Irish nationality, (just under 5 per cent of the sample of circa 1,600). As expected, non-Irish nationals were evenly distributed across both months and the control and treatment groups. This modification to the sample left most of the findings unchanged, but there were some small differences to the findings reported earlier in this chapter that are described below and referenced above where relevant.

Among respondents aged 50 and older, the difference between directly and anonymously expressed attitudes towards the Black ethnic group dropped from 10.9 per cent to 9.6 per cent. This was enough to increase the $p$-value from 0.09 to 0.12 , thus rendering it an insignificant difference by our standards of confidence and implying no masking among older respondents using this smaller sample. The difference between the directly and anonymously expressed scores also narrowed for people under 50 on the question about 
the Muslim group. In the original analysis, we found that 10.7 per cent of this sub-sample masked, and that this was significant at the 10 per cent level. With non-Irish nationals excluded, the gap dropped to 8.8 per cent and became statistically insignificant, suggesting no significant masking among respondents aged less than 50 using the smaller sample.

However, there were also some slight differences in findings using the smaller sample which suggested greater masking among the less educated group. We found in the original analysis that 8.5 per cent of the population masked negative attitudes towards Black immigrants. This changed to 11.4 per cent when we excluded non-Irish respondents, and the $p$-value was reduced from just under 0.10 to just under 0.05 . Similarly, among those who do not experience financial stress, we found that excluding the non-Irish increased the gap between directly and anonymously expressed support for Muslim immigration from a statistically insignificant 9.6 per cent to a marginally significant 10.1 per cent $(p$-value $=0.097)$

We believe that it is best practice to report the analysis of the full sample (including nonIrish nationals) in the main body of this report. The study seeks to tap the attitudes of the population in Ireland towards more Black and Muslim people coming to Ireland. Because non-Irish nationals form a part of the non-Irish population, and because their attitudes to different groups are also important, there was no reason to exclude them.

\subsection{DO ANONYMOUSLY EXPRESSED SCORES DIFFER BETWEEN GROUPS?}

Table 4.1 compares scores on the anonymously expressed item between categories on the four socio-demographic variables and formally tests the differences. We present $p$-values below each comparison to assess whether the differences between the categories are statistically significant. Conventionally, $\mathrm{p}$-values at or below 0.05 are deemed to be significant, and we highlight these results in the Table. The purpose of this analysis is to see to what extent widely held understandings about the relationship between personal characteristics and attitudes to diversity hold when analysing attitudes expressed under conditions of anonymity.

We see that when we consider anonymously expressed support, there are only two significant differences between groups. Men are significantly more positive about Muslim 
people coming to Ireland than women, and those under 50 are significantly more positive than those aged 50 and older about Black immigration.

TABLE 4.1 GROUP VARIATION IN ANONYMOUSLY EXPRESSED SUPPORT FOR MORE BLACK AND MUSLIM PEOPLE COMING TO IRELAND

\begin{tabular}{|c|c|c|c|}
\hline & & Black & Muslim \\
\hline \multirow{3}{*}{ Gender } & Male & $51 \%$ & $67 \%$ \\
\hline & Female & $51 \%$ & $40 \%$ \\
\hline & P-value & 0.98 & 0.00 \\
\hline \multirow{4}{*}{ Age } & Under 50 & $59 \%$ & $54 \%$ \\
\hline & 50 and older & $40 \%$ & $53 \%$ \\
\hline & P-value & 0.04 & 0.88 \\
\hline & Leaving Certificate or below & $49 \%$ & $59 \%$ \\
\hline \multirow[t]{2}{*}{ Educational Attainment } & Third-Level Education & $54 \%$ & $45 \%$ \\
\hline & P-value & 0.53 & 0.12 \\
\hline \multirow{3}{*}{ Financial Stress } & Low or no Financial Stress & $58 \%$ & $49 \%$ \\
\hline & High or some Financial Stress & $47 \%$ & $58 \%$ \\
\hline & P-value & 0.20 & 0.32 \\
\hline
\end{tabular}

Source: Own calculations based on Economic Sentiment Monitor, June and July 2017.

Note: Anonymously expressed scores derived from the lists. Data are weighted.

In some ways, however, the most interesting findings here are the similarities between groups rather than the differences. In the context of the existing literature, it is striking that third-level education does not result in significantly more positive attitudes towards either group. It is also surprising that the negative relationship between age groups and attitudes towards Black people is not sustained for attitudes towards Muslims, at least for the relatively wide age bands used here. Finally, financial stress has no significant effect on anonymously expressed support for these groups. Although people experiencing financial stress appear to be more positive towards immigration by Muslims, the opposite is the case for attitudes towards immigration by Black people. However, neither difference is statistically significant.

\subsection{CHAPTER SUMMARY}

The analysis in this chapter shows that social desirability is influenced by both the characteristics of the minority group in question - Black or Muslim - and by the characteristics of the respondents themselves. We find that people are more likely to mask negative opinions when asked about the Black ethnic group than the Muslim group, resulting in similar anonymously expressed support for each group. 
Social desirability is found to vary by the age and educational attainment of the respondent. People aged under 50 are more likely to mask negative opinions about both Black people and Muslim people coming to Ireland. In fact, we detect no significant masking among survey respondents aged 50 and over with respect to the question on the Muslim group. A similar picture emerges with educational attainment. One-in-four people with a third-level qualification 'overstate' their support: they do not support more Black people coming to Ireland but choose to conceal this when asked directly. One-fifth of the higher-educated group conceal negative attitudes towards Muslim immigration. By contrast, only 8.5 per cent of respondents with the equivalent of a Leaving Certificate or lower mask their attitudes to Black immigration, and we find no significant masking for the lower-educated with respect to immigration by Muslims.

Finally, evidence emerges that there is an important relationship between the group in question and the gender of the respondent. We see that almost twice as many men hold but conceal lack of support for Black immigration (21 per cent compared to 9.6 per cent), but that this gender pattern is reversed on the question of more immigration by Muslims. Here we find no significant masking among men, but that over a fifth of women conceal their lack of support for Muslim immigration.

These differential rates of masking across sub-groups of the population mean that patterns of positivity towards immigration change considerably when using anonymously expressed measures instead of direct survey items. When we guarantee respondents' permanent anonymity, we see that group differences in responses are much smaller. Only two differences are statistically significant - women are more negative towards more Muslim immigration than men; and respondents aged 50 and older are more negative towards Black immigration than younger people. However, no effect of education (third-level versus Leaving Certificate equivalent or less) or financial stress (low versus high stress) was found for either group when considering anonymously expressed measures. 


\section{CHAPTER 5}

\section{Summary and implications of findings}

\subsection{SUMMARY OF FINDINGS}

Ireland has become considerably more diverse in terms of ethnic, national and religious origin in recent decades. This study investigates how the Irish population has responded to this. Attitudinal data provide an important indicator of the climate towards groups like immigrants and ethnic and religious minorities. However, international evidence suggests that people may not reveal their true opinions to sensitive questions in a social survey, partly for fear of revealing socially undesirable answers (Krumpal, 2013). This report used an innovative technique to explore support for more Black and Muslim people coming to Ireland and to what extent this support expressed might be influenced by social desirability bias. It is the first application of this technique, the 'list experiment', in Ireland using two waves of a nationally representative Economic Sentiment Monitor in the summer of 2017.

A major finding of the report (see Figure 4.2) is that social desirability is significantly more prominent in questions relating to Black people than to Muslim people. This suggests that many people in Ireland who hold negative attitudes towards Muslims believe that their opinions are socially acceptable, unlike people who hold negative attitudes towards Black immigration. This echoes previous findings on attitudes to Muslims in the United States and respondents' willingness to express negative attitudes towards them (Creighton and Jamal, 2015; Creighton et al., 2016; Benzeval et al., 2017).

When asked directly, there is greater support among the Irish population for Black people coming to Ireland (66 per cent), than for Muslim people coming to Ireland (59 per cent). When offered anonymity in the list experiment, support for Black and Muslim immigration are at the same level - about half of the population support each. About 15 per cent of the population mask lack of support for the Black ethnic group, but we find no such evidence for attitudes to Muslims.

Previous research in Ireland and abroad using direct questions from survey data finds a large difference between highly educated respondents and those with lower education in terms 
of attitudes to immigrants and immigration. A striking finding of this report is that under conditions of anonymity no such education differences are found, at least in this sample. Using a direct question, 80 per cent of highly educated respondents support more Black people coming to Ireland, compared to 55 per cent of those with no post-secondary qualifications (Leaving Certificate or lower). When we analyse the List results, support falls to 54 per cent for those with higher education, and to 49 per cent with lower education. When we consider anonymously expressed attitudes, there is no statistically significant difference by educational attainment on this item. A similar pattern of greater masking among the more highly educated is found in attitudes to Muslim immigration, though to a lesser extent. This suggests that at least for Ireland, much of the education differences in openly expressed attitudes to immigrants and minority groups may be due to social desirability bias. It is not that the highly educated have learned tolerance to diversity, instead they have learned to conceal socially undesirable attitudes. This finding is important because people who make decisions - for example in the workplace, the housing market, in financial institutions and in policymaking - in Ireland are much more likely to be highly educated.

These findings are consistent with the qualitative work of Byrne (2014), 'Performing Distance' who finds resistance to immigration, particularly to immigrants from minority ethnic groups, among a group of highly educated Irish professionals. Yet this resistance is carefully hidden in everyday interaction by a range of strategies.

Another finding in this report concerns the age of respondents, albeit using two very wide age bands. Responses to the direct question indicate that those aged less than 50 are more supportive of these groups than those aged 50 or older. However, because the under 50 s are much more likely to mask their lack of support, the age differences in anonymously expressed scores are not so marked. Nearly 60 per cent of under 50 s support Black immigration compared to 40 per cent of those aged 50 and over according to the lists. There are no age differences in anonymously expressed support for Muslim immigration, just over half of each age group support more Muslims coming to Ireland. It is not that those aged under 50 are more tolerant of Muslims than those aged 50 or older, they are simply more likely to hide or mask negative attitudes. 
Gender differences in masking of negative attitudes vary according to the immigrant group in question. Men are substantially more likely to mask lack of support for the Black ethnic group, but masking of lack of support for Muslims is confined to women. Twenty-one per cent of men conceal lack of support for Black immigration compared to 10 per cent of women. While men seem more supportive when asked directly, there is no gender difference in attitudes towards Black immigration under conditions of anonymity (just over half of men and women support more Black people coming to Ireland). Women, by contrast, mask negativity towards Muslims to a much greater extent. Over one-fifth of women hold but conceal their lack of support for Muslims in the survey. While there is no difference between men and women in terms of support for Muslim people coming to Ireland when asked directly, a large and statistically significant gender difference appears on anonymously expressed scores, with women being much less supportive of Muslim immigration to Ireland (40 per cent support this) than men (67 per cent support this).

\subsection{LIMITATIONS AND AVENUES FOR FUTURE RESEARCH}

An obvious limitation of this report is that it does not consider attitudes to White immigration. Research from the UK and the Netherlands found significant masking of attitudes towards White immigrants (Creighton et al., 2018; Creighton et al., 2016; Benzeval et al., 2017). White immigrants are less likely to experience discrimination than Black immigrants in a range of domains in Ireland (McGinnity et al., 2017), and data from the European Social Survey suggest Irish respondents are more supportive of White immigrants coming to Ireland than different ethnic groups (McGinnity et al., 2018a; Fahey et al., 2019). However, this does not rule out an element of hidden intolerance which would be interesting to investigate.

As discussed above, evidence on how attitudes influence behaviour is somewhat lacking. The list experiment technique is limited in this regard given that it is not possible to directly investigate the link between anonymously-expressed attitudes elicited from list experiments and individual-level behaviours. This is because the design of the list technique means that the anonymously-expressed attitudes of any given individual are not identified in list experiments, in order to preserve respondent anonymity and 'allow' respondents to reveal socially undesirable responses. The concept of 'permanent anonymity' means that while 
researchers can compare group-level differences between direct and anonymous responses, the masking of negative attitudes cannot be attributed to any individual respondent.

Notwithstanding the limits of this technique, further research using different methods about how attitudes influence behaviour could enhance our understanding of the implications of attitudes to different groups. Perhaps the most promising avenue is in the area of laboratory experiments, either using vignette studies in employment or housing, followed by questions on (explicit) attitudes, or the Implicit Association Test of implicit attitudes (see Chapter 2). An alternative experiment would test behaviour towards different ethnic groups (for example through trust or gift-giving games) in a laboratory setting and follow up with questions probing either implicit or explicit attitudes.

The findings of this report, combined with the fact that the list experiment can be incorporated relatively easily and cheaply into social surveys, makes a strong case for including a list for sensitive questions on standard social surveys in Ireland, or indeed international surveys like the European Social Survey or the Eurobarometer. Including list experiments in European-wide surveys would permit comparisons of social desirability bias and anonymously expressed attitudes across Europe. At present it is difficult to compare Ireland to other countries in this regard due to differences in question wording in individual experiments.

Given evidence of socially desirable responses to immigration from different minority groups in this experiment, it would be interesting to use the method to investigate other social attitudes and attitudes to other equality groups in Ireland, such as gays and lesbians, Travellers, or people with disabilities. The list technique could also be applied to social distance scales - how respondents would feel about having someone from a specific group as their colleague or boss, and how response patterns are affected by social desirability bias.

As the technique has also been used to investigate socially undesirable behaviour such as marital infidelity and shoplifting (Krumpal, 2013), it could be used to investigate not only attitudes to diversity but past discriminatory behaviour towards different groups. For example, a more focused list experiment of employers or landlords could ask whether they had turned down someone on the basis of minority group membership. Using the list 
method could address some of the concerns regarding socially desirable responses about discriminatory behaviour.

\section{$5.3 \quad$ IMPLICATIONS}

Investigating and reporting covert or hidden attitudes does not mean that openly expressed hostility to (or support for) certain groups is not important. After all, much of social life is carried out in the open - from everyday social interaction to major social protests. For minority groups, it is a very different experience to live in a society that is openly intolerant of them than one where negative views may be held but not expressed. It is likely that different types of attitudes (openly and anonymously expressed) will result in different kinds of behaviour and in different outcomes for the minority groups in question.

\section{Attitudes, behaviours and outcomes}

There is substantial evidence that openly expressed negativity towards minority groups can harm health and well-being among members of these groups. Openly expressed antagonism like racial harassment may have damaging consequences, both in terms of mental and physical health and well-being (Wallace et al., 2016). Williams and Medlock (2017) report on a body of research in the United States which suggests that negative news or media coverage of an ethnic or racial group can have a detrimental impact on health among members of that group. Harassment and negative media coverage are also linked to perceptions of discrimination, which in turn affect well-being and migrant integration (Safi, 2010).

Covert attitudes might be more likely to impact on behaviours and decisions that occur in private. Indeed, international evidence on the link between (openly expressed) negative attitudes and discriminatory behaviour tends to highlight socially desirable responding as being one reason why attitudes towards ethnic minorities are not always good predictors of discriminatory behaviour uncovered using field experiments (Pager and Quillian, 2005; Carlsson and Rooth, 2012). In addition, some laboratory experiments indicate that subtle attitudes best predict subtle (but powerful) behaviours, whereas overt attitudes predict overt behaviours (Dovidio et al., 2002). This suggests that anonymously expressed attitudes 
to groups might be a better predictor of some types of behaviour than directly expressed attitudes. $^{19}$

One important example of a private decision is recruitment. Employers may be openly tolerant of one group, such as the Black ethnic group, but their covert beliefs may influence their decisions about who to hire. Indeed, this report's finding that people are much more negative towards Black people coming to live here when asked indirectly is consistent with existing research which has found very high levels of recruitment discrimination experienced by the Black ethnic group in Ireland (McGinnity et al., 2017; 2018c).

Another example of a private behaviour/decision is voting. Some international research has found that estimates of support for political candidates from list experiments better predict election results than estimates from traditional surveys or polls. Kalinin (2016) investigates the puzzling finding that the results of the 2012 Russian presidential election tend to match pre- and post-election polls quite closely, despite there being evidence of widespread electoral fraud. He shows that when masking of anti-incumbent opinions is accounted for, the polls no longer match the election result.

\section{Responding to openly and anonymously expressed attitudes}

Sociological approaches to studying discrimination highlight how the behaviour of individuals may be mediated by organisational practices or state policy (Reskin, 2003). Characteristics of organisations may constrain the biasing effects of either cognitive or attitudinal biases (Reskin, 2000). One important example of this is the use of formal, rationalised procedures in an organisation for recruitment and promotion. Formalisation reduces individual discretion, and the ability to act on either openly expressed or hidden bias, and this may be linked to increased representation of minorities in an organisation (Pager and Shepherd, 2008). While formalisation does not always reduce or eliminate discrimination, formal procedures could be associated with less discrimination: future research in Ireland could investigate whether there is any evidence of this. experiments and individual-level behaviours. This is because in order to provide complete and permanent anonymity, the masking of attitudes by any given individual in the experiment cannot be identified (see Section 5.3 for further discussion). 
For developing interventions to change discriminatory attitudes, knowing people's anonymously expressed preferences, not just what they openly express, may be informative. A different approach might be required to challenge and potentially modify beliefs that are held but not expressed. Has any given intervention, such as a public information campaign, led to a change in participants' anonymously expressed preferences, or simply a change in socially desirable responding? Such a campaign might best be evaluated by assessing its effect on both explicit and hidden opinions.

Perhaps the population is more similar in its attitudes than expected - these findings suggest that it is not so much that those with lower education are less tolerant of diversity, but rather those with higher education are better at masking their intolerance. This points to population-wide efforts to bring about attitudinal change, rather than targeting particular segments of the population. Overall this experiment is an attempt to stimulate a discussion of how to address negative attitudes using a more targeted, nuanced approach which acknowledges the role of social desirability bias.

What are the lessons learned? The key point from a policy perspective is to be aware of how different types of attitudes are likely to be linked to discrimination in different arenas. As an example, while overtly expressed negativity may manifest itself as openly abusive behaviour in the workplace, negative anonymously expressed attitudes towards minority groups will more likely be associated with preferential treatment and refusals of promotion. Similarly, overtly expressed negativity could result in racial harassment on public transport, while negative covert attitudes could mean that minorities would be turned down for accommodation without ever finding out why. Any attempt to raise the quality of dialogue on human rights and equality in Ireland could be usefully informed by research on both overtly and anonymously expressed attitudes to minority groups. In terms of fostering interculturalism, while directly expressed opinions are important, efforts are also needed to combat more subtle, covert or coded forms of prejudice and discrimination. 



\section{REFERENCES}

Arnold, H.J. and D.C. Feldman (1981). 'Social Desirability Response Bias in Self-Report Choice Situations', The Academy of Management Journal 24: 377-385.

Aronow, P.M., A. Coppock, F.W. Crawford and D.P. Green (2015). 'Combining List

Experiment and Direct Question Estimates of Sensitive Behavior Prevalence', Journal of Survey and Statistical Methodology, Vol. 3(1), pp. 43-66.

Bazo Vienrich, A. and M. Creighton (2018). 'What's left unsaid? In-group solidarity and ethnic and racial differences in opposition to immigration in the United States', Journal of Ethnic and Migration Studies, Vol. 44(13), pp. 2240-2255.

Benzeval, M; A. Bianchi, M. Brewer, J. Burton, A. Cernat, M.J. Creighton, T. Crossley, A. Delavande, P. Fisher, A. Gaia, A. Jäckle, A. Jamal, D. Oberski, F. Popham, E. Whitley, J. Winter and B. Zafar (2017). Understanding Society Innovation Panel Wave 9: Results from Methodological Experiments. Institute of Social and Economic Research, University of Essex, UK.

Blair, G. and K. Imai (2012). 'Statistical Analysis of List Experiments', Political Analysis, 20(1) 47-77.

Blumer, H. (1969). 'The Methodological Position of Symbolic Interactionism', in Symbolic Interactionism: Perspective and Method. Berkley: University of California Press.

Byrne, M. (2014). 'Performing Distance: The Response of Irish Professionals to Immigrants and Immigration'. Unpublished doctoral thesis, Trinity College, Dublin.

Carlsson, M. and D. Rooth, 2012. 'Revealing taste-based discrimination in hiring: a correspondence testing experiment with geographic variation', Applied Economics Letters, 19(18), pp.1861-1864.

Carr, J. (2016). Islamophobia in Dublin: Experiences and how to Respond. Dublin: Immigrant Council of Ireland. 
Ceobanu, A.M. and X. Escandell (2010). 'Comparative Analyses of Public Attitudes toward Immigrants and Immigration Using Multinational Survey Data: A Review of Theories and Research', Annual Review of Sociology, Vol. 36, pp. 309-328.

Coenders, M. and P. Scheepers (2003). 'The Effect of Education on Nationalism and Ethnic Exclusionism: An International Comparison', Political Psychology, Vol. 24 (2) pp. 313-343.

Coutts, E., B. Jann, I. Krumpal and A.-F. Näher, 2011. 'Plagiarism in Student Papers: Prevalence Estimates using Special Techniques for Sensitive Questions', Journal of Economics and Statistics, 231(5/6) 749-760.

Creighton, M. (forthcoming). 'Stigma and the Meaning of Social Desirability: Concealed Islamophobia in the Netherlands' in P. Brenner (ed.) Understanding Survey Methodology: Sociological Theory and Applications SAGE (US).

Creighton, M. and A. Jamal (2015). 'Does Islam play a role in anti-immigrant sentiment? An experimental approach', Social Science Research, 53, pp. 89-103.

Creighton, M.J. and Z. Strabac (forthcoming). Party affiliation and support for Muslim newcomers: Masked opposition in the Norwegian context, European Societies.

Creighton, M., A. Jamal and N. Malancu (2015). 'Has Opposition to Immigration Increased in the United States after the Economic Crisis? An Experimental Approach', International Migration Review, 49:727-756.

Creighton, M.J., J. Dykem, A. Gaial, A. Cernat, D. Garbarski, A. Jamal, O. Kaminski, F. Keush, P. Lynn, D. Oberski, N. Cate Schaeffer, N. Uhrig, T. Yan and T. Al Baghal (Ed.) (2016). Understanding Society Innovation Panel Wave 8: Results from Methodological Experiments. Institute of Social and Economic Research, Institute of Social and Economic Research, University of Essex, UK. 
Creighton, M., P. Schmidt and D. Zavala-Rojas (2019a). 'Race, Wealth and the Masking of Opposition to Immigrants in the Netherlands', International Migration, 57, pp. 245-263.

Creighton, M.J., D. Zavala-Rojas, P. Schmidt and P.S. Brenner (2019b). 'Application of a List Experiment at the Population Level: The Case of Opposition to Immigration in the Netherlands', in Lavrakas, P.J., M.W. Traugott, C. Kennedy, A.L. Holbrook, E.D. de Leeuw and B.T. West (Ed.) Experimental Methods in Survey Research: Techniques that Combine Random Sampling with Random Assignment, Wiley: New York (US).

CSO (2018). Population Usually Resident and Present in the State 2011 to 2016 by Age Group, Sex, Birthplace and Census Year. Statbank Table E7055.

Davis, D.W. and B.D. Silver (2003). 'Stereotype Threat and Race of Interviewer Effects in a Survey on Political Knowledge', American Journal of Political Science 47:33-45.

De Geus, R. (2017). 'In Polls We Do Not Trust: the British Polling Experience'. Oxford Q-Step Centre. Available: https://www.oqc.ox.ac.uk/news/in-polls-we-do-not-trust-the-britishpolling-experience.html Accessed December 2018.

Dovidio, J., K. Kawakami and S. Gaertner, 2002. 'Implicit and explicit prejudice and interracial interaction', Journal of Personality and Social Psychology, 82(1), pp. 62-68.

Duffy, D., C. Morley and D. Watson (2015). The KBC Bank/ESRI Consumer Sentiment Index. ESRI Research Note, 2015/2/2.

Eurostat (2017). 'Population on 1 January by age group, sex and country of birth' [migr_pop3ctb] (Accessed September 2018).

Fahey, E., F. McGinnity and R. Grotti (2019). 'Irish attitudes to Muslim Immigrants', The Economic and Social Review, Vol. 50 (3).

Fowler, F.J. (1995). Improving Survey Questions: Design and Evaluation. Sage: Thousand Oaks. 
FRA (European Union Agency for Fundamental Rights) (2017). Second European Union Minorities and Discrimination Survey: Technical Report. Luxembourg: Publications Office of the European Union.

FRA (European Union Agency for Fundamental Rights) (2018). Second European Union Minorities and Discrimination Survey: Being Black in the EU. European Union Agency for Fundamental Rights. Luxembourg: Publications Office of the European Union.

Glynn, A.N. (2013). 'What Can We Learn with Statistical Truth Serum? Design and Analysis of the List Experiment', Public Opinion Quarterly, Vol. 77, pp. 159-172.

Goffman, E. (1959). The Presentation of self in everyday life, New York: Random House.

Goffman, E. (1963). Stigma: Notes on the management of spoiled identity, New York: Simon and Schuster.

Grotti, R., H. Russell, E. Fahey and B. Maître (2018). Discrimination and Inequality in Housing in Ireland. ESRI/IHREC, Research Series.

Gusciute, E. (2019). 'All Welcome Here? Studies on Anti-Immigration Attitudes and Discriminatory Behaviour towards Ethnic Minorities in Irish and European Contexts', Unpublished doctoral thesis, Trinity College Dublin.

Hagendoorn, L. (2016). 'Ethnic categorization and outgroup exclusion: cultural values and social stereotypes in the construction of ethnic hierarchies', Ethnic and Racial Studies, Vol. 16 , no. $1,1993,26 / 51(27)$.

Hainmueller, J. and M.J. Hiscox (2007). 'Educated Preferences: Explaining Attitudes toward Immigration in Europe', International Organisation, Vol. 61(2), pp. 399-442.

Hainmueller, J. and M. Hiscox, 2010. 'Attitudes toward Highly Skilled and Low-skilled Immigration: Evidence from a Survey Experiment', American Political Science Review, 104(1), 61-84. 
Hayes, B.C. and L. Dowds (2006). 'Social Contact, Cultural Marginality or Economic SelfInterest? Attitudes towards Immigrants in Northern Ireland', Journal of Ethnic and Migration Studies, 32(3), pp. 455-476.

Heerwegh, D. (2009). 'Mode Differences Between Face-to-Face and Web Surveys: An Experimental Investigation of Data Quality and Social Desirability Effects', International Journal of Public Opinion Research, 21:111-121.

Heerwig, J.A. and B.J. McCabe (2009). 'Education and social desirability bias: the case of a black presidential candidate', Social Science Quarterly, Vol. 90, pp. 674-686.

Helbling, M. (2012). Islamophobia in the West: Measuring and Explaining Individual Attitudes. Routledge: London.

Helbling, M. and R. Traunmüller (2018). 'What is Islamophobia? Disentangling Citizens' Feelings Toward Ethnicity, Religion and Religiosity Using a Survey Experiment', British Journal of Political Science, pp. 1-18.

Holbrook, A.L. and J.A. Krosnick (2010). 'Social desirability bias in voter turnout reports: Tests using the item count technique', Public Opinion Quarterly 74(1): 37-67.

Kalinin, K. (2016). 'The social desirability bias in autocrat's electoral ratings: evidence from the 2012 Russian presidential elections', Journal of Elections, Public Opinion and Parties, 26(2), pp.191-211.

Jackman, M.R. and M.J. Muha (1984). 'Education and Intergroup Attitudes: Moral Enlightenment, Superficial Democratic Commitment, or Ideological Refinement?', American Sociological Review, Vol. 49(6), pp. 751-69.

Janus (2010). 'The Influence of Social Desirability Pressures on Expressed Immigration Attitudes', Social Science Quarterly, 91(4), pp. 925-946.

Kalkan, K.O., G.C. Layman and E.M. Uslaner (2009). "'Bands of Others”? Attitudes toward Muslims in Contemporary American Society', The Journal of Politics, Vol. 71(3), pp. 1-16. 
Kiewiet de Jonge. C.P. and D. Nickerson (2014). 'Artificial inflation or deflation? Assessing the item count technique', Political Behavior 36(3), pp. 659-682.

Knoll, B.R. (2013a). 'Assessing the effect of social desirability on nativism attitude responses', Social Science Research, Vol. 42(6), pp. 1587-98.

Knoll, B.R. (2013b). 'Implicit Nativist Attitudes, Social Desirability, and Immigration Policy Preferences', International Migration Review, Vol. 47, pp. 132-165.

Krumpal, I. (2013). 'Determinants of Social Desirability Bias in Sensitive Surveys: A Literature Review', Quality and Quantity, Vol. 47, pp. 2025-2047.

Kuhn, M.H. (1964). 'Major trends in symbolic interactionist theory in the past twenty-five years', The Sociological Quarterly 5: 61-84.

Kuklinski, J.H., M.D. Cobb and M. Gilens (1997a). 'Racial attitudes and the "New South"', Journal of Politics, Vol. 59, pp. 323-49.

Kuklinski, J.H., P.M. Sniderman, K. Knight, T. Piazza, P.E. Tetlock, G.R. Lawrence and B. Mellers (1997b). 'Racial prejudice and attitudes toward affirmative action', American Journal of Political Science, Vol. 41, pp. 402-19.

Kuppens, T. and R. Spears (2014). 'You don't have to be well-educated to be an aversive racist, but it helps', Social Science Research, Vol. 45, pp. 211-223.

Kuran, T. and E.J. McCaffery (2008). 'Sex Differences in the Acceptability of Discrimination', Political Research Quarterly, Vol. 61, pp. 228-238.

Mac Gréil, M. (2011). Pluralism and Diversity in Ireland. Dublin: Colombia Press.

Mayda, A. (2006). 'Who Is Against Immigration? A Cross-Country Investigation of Individual Attitudes toward Immigrants', Review of Economics and Statistics, Vol. 88(3), pp. $510-30$. 
McGinnity, F. and M. Gijsberts (2016). 'A threat in the air? Perceptions of group discrimination in the first years after migration: Comparing Polish Migrants in Germany, the Netherlands, the UK and Ireland', Ethnicities, Vol. 16, No. 2.

McGinnity, F. and G. Kingston (2017). 'An Irish Welcome? Changing Irish Attitudes to Immigrants and Immigration: The Role of Recession and Immigration', The Economic and Social Review, 48(3), pp. 253-279.

McGinnity, F. and P. Lunn (2011). 'Measuring Discrimination Facing Ethnic Minority Candidates: An Irish Experiment', Work, Employment and Society, Vol. 25(4), pp. 693-708.

McGinnity, F., D. Watson and G. Kingston (2012). Analysing the Experience of Discrimination in Ireland: Evidence from the QNHS Equality Module 2010.

McGinnity, F., R. Grotti, S. Groarke and S. Coughlan (2018c). Ethnicity and Nationality in the Irish Labour Market. ESRI/IHREC, Research Series.

McGinnity, F., E. Quinn, E. Fahey, S. Arnold, B. Maître and P.J. O'Connell (2018b). Monitoring Report on Integration 2018. DJE/ESRI, Research Series.

McGinnity, F., R. Grotti, H. Russell and E. Fahey (2018a). Attitudes to Diversity in Ireland. Dublin: ESRI/IHREC, Research Series.

McGinnity, F., R. Grotti, O. Kenny and H. Russell (2017). Who experiences discrimination in Ireland? Evidence from the QNHS Equality Modules. ESRI/IHREC, Research Series.

Michael, L. (2016). Afrophobia in Ireland: Racism against People of African Descent. ENAR Ireland: Dublin.

Neumark, D., 2018. 'Experimental Research on Labor Market Discrimination', Journal of Economic Literature, 56(3), pp. 799-866.

Noon, M. (2018). 'Pointless Diversity Training: Unconscious Bias, New Racism and Agency', Work Employment and Society, Vol. 32(1), pp. 198-209. 
O'Connell, P.J. (2019). 'Why are so few Africans at work in Ireland? Immigration policy and labour market disadvantage', Irish Journal of Sociology. https://doi.org/10.1177/0791603519853767.

Office of the Refugee Applications Commissioner (2014). 'Annual Report - 2014'. Available: www.orac.ie/website/orac/oracwebsite.nsf/page/publications-main-en Accessed September 2018.

Pager, D. and L. Quillian (2005). 'Walking the Talk? What Employers Say Versus What They Do', American Sociological Review, 70(3), pp. 355-380.

Pager, D. and H. Shepherd (2008). 'The Sociology of Discrimination: Racial Discrimination in Employment, Housing, Credit, and Consumer Market', Annual Review of Sociology, Vol. 34, pp. 181-209.

Paradies, Y. (2006). 'A systematic review of empirical research on self-reported racism and health', International Journal of Epidemiology, 35(4), pp. 888-901.

Pettigrew, T.F. and L.R. Tropp (2011). When Groups Meet: The Dynamics of Intergroup Conflict. New York: Psychology Press.

Phillips, D.L. and K. Clancy (1972). 'Some Effects of "Social Desirability" in Survey Studies', American Journal of Sociology, 77:921-940.

Presser, S. and L. Stinson (1998). 'Data Collection Mode and Social Desirability Bias in SelfReported Religious Attendance', American Sociological Review 63:137-145.

Reskin B.F. (2000). 'The Proximate Causes of Employment Discrimination', Contemporary Sociology, Vol. 29(2), pp. 319-28.

Reskin B.F. (2003). '2002 Presidential Address: Including Mechanisms in our Models of Ascriptive Inequality', American Sociological Review, Vol. 68, pp. 1-21.

Safi M. (2010). 'Immigrants life satisfaction in Europe: Between assimilation and discrimination', European Sociological Review, 26(2): 159-176. 
Schneider, S.L. (2006). 'Anti-Immigrant Attitudes in Europe: Outgroup Size and Perceived Ethnic Threat', European Sociological Review, Vol. 24(1), pp. 53-67.

Siapera, E., E. Moreno and J. Zhou (2018). Hate Track: Tracking and Monitoring Racist Speech Online. Dublin: IHREC

Silberman, R. R. Alba and I. Fournier (2007). 'Segmented assimilation in France? Discrimination in the labour market against the second generation', Ethnic and Racial Studies, 30:1, 1-27

Snellman, A. and B. Ekehammar (2005). 'Ethnic Hierarchies, Ethnic Prejudice, and Social Dominance Orientation', Journal of Community and Applied Social Psychology, Vol. 15 No. 2, pp. 83-94.

Storm, I. (2018). 'When does religiosity matter for attitudes to immigration? The impact of economic insecurity and religious norms in Europe', European Societies, Vol. 20(4), pp. 595-620.

Strabac, Z. and O. Listhaug (2008). 'Anti-Muslim prejudice in Europe: A multilevel analysis of survey data from 30 countries', Social Science Research, Vol. 37(1), pp. 268-286.

Stryker S. (1980). Symbolic interactionism: A social structural version, Menlo Park, CA: Benjamin Cummings.

TNS (2018). Special Eurobarometer 469: Integration of immigrants in the European Union, Report. European Commission.

Verkuyten, M. and B. Kinket (2000). 'Social Distances in a Multi Ethnic Society: The Ethnic Hierarchy among Dutch Preadolescents', Social Psychology Quarterly, Vol. 63, No. 1, pp. 75-85.

Wallace, S., J. Nazroo and L. Bécares (2016). 'Cumulative Effect of Racial Discrimination on the Mental Health of Ethnic Minorities in the United Kingdom', American Journal of Public Health, 106(7), pp.1294-1300. 
Ward, C. and A. Masgoret (2008). 'Attitudes toward Immigrants, Immigration, and Multiculturalism in New Zealand: A Social Psychological Analysis', International Migration Review, 42(1):227-248.

Watson, D., O. Kenny and F. McGinnity (2017). A Social Portrait of Travellers in Ireland. Dublin: ESRI.

Williams, D.R. and M.D. Medlock (2017). New England Journal of Medicine; 376:2295-2299. https://doi.org/10.1056/NEJMms1702111

Zschirnt, E. and D. Ruedin (2016). 'Ethnic Discrimination in Hiring Decisions: A Meta- analysis of Correspondence Tests 1990-2015', Journal of Ethnic and Migration Studies, 42/ 7: 11151134. 


\section{APPENDIX 1}

Formally, the list experiment designed for this work consists of two steps. First, we subtract the mean response to the control list from the mean response to the treatment list to ascertain the anonymously expressed support for the additional focal item - Black or Muslim immigration. This is formalised in Equation 1

$$
E=\bar{X}_{B}-\bar{X}_{A}
$$

where $E$ represents the proportion of the sample that select the focal item in the treatment list, which is derived from the difference between the mean response to the treatment list $\left(\bar{X}_{B}\right)$ and the mean response to the control list $\left(\bar{X}_{A}\right)$. A two-sample, one-sided t-test offers a formal test as to whether the proportion selecting the focal item in the treatment is significantly greater than zero. Although the difference between the two list questions provides a measure of anonymously expressed support for the focal item, the extent to which attitudes are hidden requires comparing the estimate of $E$ to a direct question (D) about perception of either Black or Muslim people coming to Ireland.

Responses to the direct question are either 'yes' or 'no' and the interpretation is equivalent to a standard direct survey with no effort to mitigate social desirability bias. Capturing openly expressed support, the proportion who respond favourably to the direct question can be subtracted from the proportion derived from the list experiment (Equation 1). From this comparison a measure of the proportion of the population masking their negative attitudes emerges, which is formalised by Equation 2:

$$
C=E-\bar{X}_{D}
$$

where $C$ measures the difference between the proportion expressing positive views towards Black or Muslim immigration when asked directly (i.e. $\bar{X}_{D}$, where the subscript $D$ refers to mean response to the direct question (D), which is coded as a binary 0,1 response), and the proportion who express positive attitudes when assessed via the list experiment (i.e. $E$, which is calculated using Equation 1). When converted to a percentage scale, $C$ is interpretable as the percentage-point difference between openly expressed tolerance and that which is expressed when permanent anonymity is offered. In sum, Equations 1 and 2 provide three key measures: (1) tolerance expressed when asked directly, (2) tolerance 
when offered absolute anonymity and (3) the difference between the two, which measures the extent to which intolerance is masked.

Of note, recent work has considered both multivariate approaches (Blair and Imai, 2012) and alternative approaches to accommodate direct and list measures in a single framework (Aronow et al., 2015). Future work might consider alternatives that include controls to better allow comparison between groups in a given experimental group via a multivariate approach, though this adds considerable complexity to the task. This report retains the original design of the list experiment, which entails a comparison of the means from the control and treatment list. Given that the treatment and control groups were randomly assigned, we have no reason to expect findings to differ considerably, if at all, from those reported here. 


\section{APPENDIX 2}

Here we present an overview of the four Economic Sentiment Monitor surveys from which data were taken for this report. These are the control and treatment surveys for June 2017, which probed attitudes towards Black immigration, and for July 2017, which asked about attitudes towards Muslim immigration. The key difference between the control and treatment surveys are the questions in Section C of each document. The focus is on the questions that formed part of the list experiment: other questions are summarised here for information.

\begin{tabular}{|c|c|c|c|c|c|c|c|c|c|c|}
\hline \multicolumn{5}{|c|}{ June 2017 (Black) Control } & \multicolumn{6}{|c|}{ June 2017 (Black) Treatment } \\
\hline \multicolumn{11}{|c|}{ Sex of respondent } \\
\hline \multicolumn{11}{|c|}{ A1-A5: Questions on the respondent's views on the state of the economy } \\
\hline \multicolumn{11}{|c|}{ B1-B16: Questions on housing } \\
\hline \multicolumn{11}{|c|}{ C3-C7: Questions on savings } \\
\hline \multicolumn{5}{|l|}{ C21: } & \multicolumn{6}{|l|}{ C21: } \\
\hline \multicolumn{5}{|c|}{$\begin{array}{l}\text { The next questions are about your opinion on } \\
\text { a few different issues in Ireland today. }\end{array}$} & \multicolumn{6}{|c|}{$\begin{array}{l}\text { The next questions are about your opinion } \\
\text { on a few different issues in Ireland today. } \\
\text { I am going to read out four things that you } \\
\text { may or may not support. }\end{array}$} \\
\hline \multicolumn{5}{|c|}{$\begin{array}{l}\text { After I read all three, just tell me HOW MANY } \\
\text { of them you support. }\end{array}$} & \multirow{2}{*}{\multicolumn{6}{|c|}{$\begin{array}{l}\text { After I read all four, just tell me HOW MANY } \\
\text { of them you support. } \\
\text { I don't want to know which statements, just } \\
\text { HOW MANY. }\end{array}$}} \\
\hline \multicolumn{5}{|c|}{$\begin{array}{l}\text { I don't want to know which statements, just } \\
\text { HOW MANY. }\end{array}$} & & & & & & \\
\hline \multicolumn{5}{|c|}{ - Higher weekly State Pension } & \multicolumn{6}{|c|}{ HOW MANY. } \\
\hline \multicolumn{5}{|c|}{ - Lower tax on diesel } & \multicolumn{6}{|c|}{ - Lower tax on diesel } \\
\hline \multicolumn{5}{|c|}{ - Bigger fines for litter } & \multicolumn{6}{|c|}{ - Bigger fines for litter } \\
\hline \multicolumn{5}{|c|}{ How many of these would you support? } & \multicolumn{6}{|c|}{$\begin{array}{l}\text { - More Black people coming to live in } \\
\text { Ireland }\end{array}$} \\
\hline \multirow[t]{3}{*}{ None } & \multirow[t]{3}{*}{ One } & \multirow[t]{3}{*}{ Two } & \multirow[t]{3}{*}{ Three } & (Don't & \multirow{2}{*}{\multicolumn{6}{|c|}{ How many of these would you support? }} \\
\hline & & & & know) & & & & & & \\
\hline & & & & & \multirow[t]{2}{*}{ None } & \multirow[t]{2}{*}{ One } & \multirow[t]{2}{*}{ Two } & \multirow[t]{2}{*}{ Three } & \multirow[t]{2}{*}{ Four } & (Don't \\
\hline$\square 0$ & $\square_{1}$ & $\square_{2}$ & $\square_{3}$ & $\square$ g & & & & & & know) \\
\hline \multirow{2}{*}{\multicolumn{5}{|c|}{$\begin{array}{l}\text { C22: } \\
\text { Would you support more Black people coming } \\
\text { to live in Ireland? }\end{array}$}} & $\square 0$ & $\square_{1}$ & $\square_{2}$ & $\square_{3}$ & $\square_{4}$ & $\square 9$ \\
\hline & & & & & & & & & & \\
\hline Yes .... [ & & & $\ldots . \square_{2}$ & & & & & & & \\
\hline
\end{tabular}




\begin{tabular}{|c|c|c|c|c|c|c|c|c|c|c|}
\hline \multicolumn{5}{|c|}{ July 2017 (Muslim) Control } & \multicolumn{6}{|c|}{ July 2017 (Muslim) Treatment } \\
\hline \multicolumn{11}{|c|}{ Sex of respondent } \\
\hline \multicolumn{11}{|c|}{ A1-A5: Questions on the respondent's views on the state of the economy } \\
\hline \multicolumn{11}{|c|}{ B1-B16: Questions on housing } \\
\hline \multicolumn{11}{|c|}{ C3-C7: Questions on savings } \\
\hline \multicolumn{5}{|c|}{$\begin{array}{l}\text { C21: } \\
\text { The next questions are about your opinion on } \\
\text { a few different issues in Ireland today. } \\
\text { I am going to read out three things that you } \\
\text { may or may not support. } \\
\text { After I read all three, just tell me HOW MANY } \\
\text { of them you support. } \\
\text { I don't want to know which statements, just } \\
\text { HOW MANY. }\end{array}$} & \multicolumn{6}{|c|}{$\begin{array}{l}\text { C21: } \\
\text { The next questions are about your opinion } \\
\text { on a few different issues in Ireland today. } \\
\text { I am going to read out four things that you } \\
\text { may or may not support. } \\
\text { After I read all four, just tell me HOW MANY } \\
\text { of them you support. } \\
\text { I don't want to know which statements, just } \\
\text { HOW MANY. }\end{array}$} \\
\hline \multicolumn{5}{|c|}{$\begin{array}{l}\text { - Higher weekly State Pension. } \\
\text { - Lower tax on diesel } \\
\text { - Bigger fines for litter }\end{array}$} & $\begin{array}{l}\text { - } \mathrm{Hi} \\
\text { - Lo } \\
\text { - } \mathrm{Bi} \\
\text { - } \mathrm{M} \\
\text { Irela }\end{array}$ & $\begin{array}{l}\text { gher w } \\
\text { wer tax } \\
\text { gger fin } \\
\text { ore Mu } \\
\text { ind }\end{array}$ & $\begin{array}{l}\text { ekly St } \\
\text { on dies } \\
\text { s for li } \\
\text { lim pec }\end{array}$ & $\begin{array}{l}\text { te Pensi } \\
\text { el } \\
\text { ter } \\
\text { ple com }\end{array}$ & $\begin{array}{l}\text { on. } \\
\text { ing to }\end{array}$ & live in \\
\hline \multicolumn{5}{|c|}{ How many of these would you support? } & \multicolumn{6}{|c|}{ How many of these would you support? } \\
\hline None & One & Two & Three & $\begin{array}{l}\text { (Don't } \\
\text { know) }\end{array}$ & None & One & Two & Three & Four & $\begin{array}{l}\text { (Don't } \\
\text { know) }\end{array}$ \\
\hline$\square 0$ & $\square_{1}$ & $\square_{2}$ & $\square_{3}$ & $\square 9$ & $\square_{0}$ & $\square_{1}$ & $\square_{2}$ & $\square_{3}$ & $\square_{4}$ & $\square 9$ \\
\hline \multicolumn{11}{|c|}{$\begin{array}{l}\text { C22: } \\
\text { Would you support more Muslim people } \\
\text { coming to live in Ireland? }\end{array}$} \\
\hline Yes .... [ & & &..$\square_{2}$ & & & & & & & \\
\hline
\end{tabular}


16-22 Sráid na Faiche,

Baile Átha Cliath 7, D07 CR20

16-22 Green Street,

Dublin 7, D07 CR20

Guthán/Phone + 353 (0) 18589601

Ríomhphost/Emailinfo@ihrec.ie

Idirlíon/Web www.ihrec.ie
Whitaker Square,

Sir John Rogerson's Quay Dublin 2

Phone +35318632000

Fax +35318632100

Email admin@esri.ie

Web www.esri.ie 